OPEN ACCESS

Edited by:

Ling Li,

University of Minnesota Twin Cities,

United States

Reviewed by:

G. William Rebeck,

Georgetown University, United States

Chia-Chen Liu,

Mayo Clinic Florida, United States

${ }^{*}$ Correspondence:

Leon M. Ta

leontai@uic.edu

Specialty section:

This article was submitted to

Neurodegeneration,

a section of the journal

Frontiers in Neuroscience

Received: 11 November 2020

Accepted: 20 January 2021

Published: 10 February 2021

Citation:

Scheinman SB, Zaldua S, Dada A,

Krochmaliuk K, Dye K, Marottoli FM,

Thatcher GRJ and Tai LM (2021)

Systemic Candesartan Treatment Modulates Behavior, Synaptic Protein

Levels, and Neuroinflammation

in Female Mice That Express Human APOE4. Front. Neurosci. 15:628403.

doi: 10.3389/fnins.2021.628403

\section{Systemic Candesartan Treatment Modulates Behavior, Synaptic Protein Levels, and Neuroinflammation in Female Mice That Express Human APOE4}

\author{
Sarah B. Scheinman', Steve Zaldua' ${ }^{1}$, Adedoyin Dada ${ }^{1}$, Kateryna Krochmaliuk', \\ Katherine Dye ${ }^{2}$, Felecia M. Marottoli ${ }^{1}$, Gregory R. J. Thatcher ${ }^{3}$ and Leon M. Tai ${ }^{1 *}$ \\ ${ }^{1}$ Department of Anatomy and Cell Biology, University of Illinois at Chicago, Chicago, IL, United States, ${ }^{2}$ UICentre, University \\ of Illinois at Chicago, Chicago, IL, United States, ${ }^{3}$ Department of Pharmacology and Toxicology, College of Pharmacy, \\ University of Arizona, Tucson, AZ, United States
}

Evidence suggests that angiotensin receptor blockers (ARBs) could be beneficial for Alzheimer's disease (AD) patients independent of any effects on hypertension. However, studies in rodent models directly testing the activity of ARB treatment on behavior and AD-relevent pathology including neuroinflammation, $A \beta$ levels, and cerebrovascular function, have produced mixed results. APOE4 is a major genetic risk factor for $A D$ and has been linked to many of the same functions as those purported to be modulated by ARB treatment. Therefore, evaluating the effects of ARB treatment on behavior and AD-relevant pathology in mice that express human APOE4 could provide important information on whether to further develop ARBs for AD therapy. In this study, we treated female and male mice that express the human APOE4 gene in the absence (E4FAD-) or presence (E4FAD+) of high $A \beta$ levels with the ARB prodrug candesartan cilexetil for a duration of 4 months. Compared to vehicle, candesartan treatment resulted in greater memory-relevant behavior and higher hippocampal presynaptic protein levels in female, but not male, E4FAD - and E4FAD+ mice. The beneficial effects of candesartan in female E4FAD - and E4FAD+ mice occurred in tandem with lower GFAP and Iba1 levels in the hippocampus, whereas there were no effects on markers of cerebrovascular function and $A \beta$ levels. Collectively, these data imply that the effects of ARBs on ADrelevant pathology may be modulated in part by the interaction between APOE genotype and biological sex. Thus, the further development of ARBs could provide therapeutic options for targeting neuroinflammation in female APOE4 carriers.

Keywords: angiotensin receptor blocker, ApoE4, female sex, memory, inflammation

\section{INTRODUCTION}

Alzheimer's disease (AD) is a progressive neurodegenerative disorder and is the leading cause of dementia worldwide. Existing treatments for $\mathrm{AD}$ are palliative and it is therefore important to identify new therapeutic targets. This issue can be addressed by evaluating the extent that pathways modulated by known $\mathrm{AD}$ risk factors contribute to $\mathrm{AD}$ etiology regardless of risk factor status. 
One such risk factor is mid-life hypertension, which is often treated with angiotensin receptor blockers (ARBs). ARBs are antagonists of the Angiotensin II Type 1 (AT1) receptor and therefore limit the vasoconstrictor activity of angiotensin II (Tzourio, 2007; Kurtz and Klein, 2009). In general, evidence suggests that managing mid-life hypertension with ARBs is beneficial for AD. For example, large-scale analyses of ARB treatment in hypertensive $\mathrm{AD}$ patients have shown a reduction in the rate of progression of the disease ( $\mathrm{Li}$ et al., 2010; Davies et al., 2011). Through these and other studies a key concept has emerged: that ARB treatment could be beneficial for AD patients independent of hypertension. For example, AT1 receptor signaling in the brain has been linked to ADrelevant behavioral and pathological changes in vivo and in vitro (Benicky et al., 2009; Saavedra, 2012a,b, 2016). However, studies in which AD-relevant rodent models have been directly treated with ARBs have produced mixed results at modifying memoryrelevant behavioral deficits, neuroinflammation, $A \beta$ levels, and cerebrovascular function (which we term AD-relevant pathology) (Wang et al., 2007; Mogi et al., 2008; Takeda et al., 2009; Tsukuda et al., 2009; Danielyan et al., 2010; Ferrington et al., 2011, 2012; Ongali et al., 2014, 2016; Torika et al., 2016, 2017, 2018; Royea et al., 2017; Trigiani et al., 2018). As repurposing ARBs could represent an attractive new therapy for $\mathrm{AD}$, it is important to fully evaluate their activity in AD-relevant models.

Evaluating the therapeutic potential of ARBs in vivo can be facilitated by utilizing models that incorporate AD genetic risk factors known to modulate functions linked to AT1 receptor signaling in the brain. $A P O E$ genotype is the greatest genetic risk factor for the development of $\mathrm{AD}$, with APOE4 increasing $\mathrm{AD}$ risk up to 12-fold compared to APOE3 (Bu, 2009; Kim et al., 2009; Holtzman et al., 2012; Huang and Mahley, 2014; Zhao et al., 2018). APOE can modulate neuronal function in the brain through a number of direct or indirect pathways both in the absence (Wolf et al., 2013) and presence (Carter, 2005; Ye et al., 2005; Tai et al., 2015) of A $\beta$. In vivo models have identified that APOE4 is associated with memory-relevant behavioral deficits (Bour et al., 2008; Liu et al., 2015), greater neuroinflammation (Guo et al., 2004), higher A $\beta$ levels (LaDu et al., 1994; Ye et al., 2005; Youmans et al., 2012; Tai et al., 2013, 2014b; Lewandowski et al., 2020), and more severe cerebrovascular dysfunction (Thomas et al., 2016, 2017; Zaldua et al., 2020), compared to APOE3. As described above, these are the same functions and pathologies purported to be altered by ARB treatment in mouse models expressing familial AD (FAD) mutations. Therefore, evaluating the effects of ARB treatment on $\mathrm{AD}$-relevant pathology in mice that express human APOE4 could provide important information on whether to further develop ARBs for AD therapy.

The goal of this study was to evaluate the activity of longer-term ARB treatment at modulating behavior and other pathological changes that are relevant for $\mathrm{AD}$ in mice that express human APOE4. To this end, we treated female and male mice that express the human APOE4 gene in the absence $(\mathrm{E} 4 \mathrm{FAD}-$ ) or presence $(\mathrm{E} 4 \mathrm{FAD}+)$ of $\mathrm{A} \beta$ overproduction (Youmans et al., 2012; Tai et al., 2017) with the ARB prodrug candesartan cilexetil for a duration of 4 months and assessed the following: plasma drug levels, blood pressure, memoryrelevant behavior, synaptic protein levels, angiotensin peptides and receptors, neuroinflammation, $\mathrm{A} \beta$ levels, and markers of cerebrovascular function.

\section{MATERIALS AND METHODS}

\section{Mouse Model and Treatment}

All experiments follow the UIC Institutional Animal Care and Use Committee protocols. E4FAD mice were produced by crossing mice that express 5 Familial Alzheimer's Disease (5xFAD) mutations (APP K670N/M671L + I716 V + V717I and PS1 M146L + L286 V) with APOE4-targeted replacement mice (Youmans et al., 2012). APOE4-targeted replacement mice are homozygous for the human APOE4 gene. E4FAD carrier mice are $A P O E^{+/+} / 5 \mathrm{xFAD}^{+/-}(\mathrm{E} 4 \mathrm{FAD}+)$ and non-carrier mice are $A P O E^{+/+} 5 \mathrm{xFAD}^{-/-}(\mathrm{E} 4 \mathrm{FAD}-)$. Female and male E4FADand $\mathrm{E} 4 \mathrm{FAD}+$ mice were used in this study as identified by genotyping of tail samples (see Supplementary Figure 1 for full $n$ sizes).

Treatments were administered in hydrogel which replaces drinking water as described in Tai et al. (2014a). Each mouse $(\sim 30 \mathrm{~g})$ consumes roughly $4.5 \mathrm{ml}$ of hydrogel per day; consumption was routinely monitored, and hydrogel was replaced three times a week to ensure fresh drug was consistently available. Candesartan cilexetil (Cayman Chemical Company) was dissolved in molecular biology grade DMSO and mixed in hydrogel (Clear $\mathrm{H}_{2} \mathrm{O}$ Inc.). Mice received hydrogel containing vehicle (0.22\% DMSO), $0.0067 \mathrm{mg} / \mathrm{ml}$ ( $1 \mathrm{mg} / \mathrm{kg} /$ day) candesartan cilexetil, or $0.067 \mathrm{mg} / \mathrm{ml}(10 \mathrm{mg} / \mathrm{kg} /$ day $)$ candesartan cilexetil. Female mice were treated from 6 months of age until 10 months of age, and male mice were treated from 8 months of age until 12 months of age. All behavioral testing was conducted blinded, however, due to issues related to COVID19, biochemical and IHC analysis was conducted unblinded.

\section{Behavioral Testing}

Behavioral analysis was conducted in the mouse dark cycle, tracked in real time by a camera, and analyzed using AnyMaze software as described in Thomas et al. (2016, 2017), Marottoli et al. $(2017,2019)$.

\section{Open Field}

A single mouse was placed in the center of a white acrylic container (1 $432 \mathrm{~mm} \times$ w $305 \mathrm{~mm} \times$ h $300 \mathrm{~mm}$ ) covered with bedding and allowed to freely explore for $7 \mathrm{~min}$. Total distance traveled and percent distance traveled in perimeter of the container were calculated (Thomas et al., 2016, 2017; Marottoli et al., 2017, 2019).

\section{Novel Object Recognition}

Open field was conducted 1 day prior to novel object recognition and therefore served as the habitation phase. Mice were placed in the center of the same testing chamber as described for the open field test, containing two identical objects placed equidistant from each other and the walls of the box, and 
allowed to explore for $7 \mathrm{~min}$. Mice were then returned to their home cage for $1 \mathrm{~h}$, after which they were placed in the testing chamber for an additional $7 \mathrm{~min}$ with a familiar and a novel object. Total investigation time of both objects as well as the preference index (ratio of time spent with the novel object divided by the total investigation time of both objects) were calculated for both phases of the test (Thomas et al., 2016, 2017; Marottoli et al., 2017, 2019). Mice that had a total investigation time of less than $20 \mathrm{~s}$ were excluded from analysis.

\section{Blood Pressure Measurement}

Blood pressure was measured using a noninvasive tail-cuff system (Kent Scientific Company). Mean arterial pressure was assessed using Volume Pressure Recording (VPR) sensor technology. Mice were habituated to the restraining device and tail cuffs for $20 \mathrm{~min}$ a day for 2 days prior to the testing day. Five additional acclimation cycles were performed before acquiring 15 measurements of mean arterial pressure which were then averaged to determine each animal's blood pressure.

\section{Tissue Processing}

Mice were deeply anesthetized with $150 \mu$ l ketamine and $50 \mu l$ xylazine (i.p), blood was drawn by cardiac puncture, and transcardial perfusion was performed using ice-cold PBS. Dissected left hemi-brains were frozen in O.C.T and stored at $-80^{\circ} \mathrm{C}$ until processing for immunohistochemical (IHC) analysis. Right hemi-brains were further dissected into the hippocampus, which was then flash frozen in liquid nitrogen and stored at $-80^{\circ} \mathrm{C}$ until processing for biochemical analysis.

\section{Biochemical Analysis}

Hippocampal samples were weighed and extracted using a 2-step extraction protocol with modifications as described previously (Youmans et al., 2012; Tai et al., 2013, 2014a; Thomas et al., 2016, 2017; Marottoli et al., 2017, 2019), in order to separate out soluble and detergent-soluble proteins. Briefly, samples were homogenized using a bead mill (Fisherbrand) at $6 \mathrm{~m} / \mathrm{s}$ for 1 cycle of $30 \mathrm{~s}$ in ice cold TBS at $10 \mu \mathrm{l} / \mathrm{mg}$ of brain tissue, centrifuged $(100,000 \times g$ for $30 \mathrm{~min})$, and aliquoted. The resulting pellet was then resuspended in SDS buffer (1\% SDS + $10 \mathrm{mM} \mathrm{NaF}+2 \mathrm{mM}$ $\mathrm{Na}_{3} \mathrm{VO}_{4}+1 \times$ protease inhibitor cocktail in $20 \mathrm{mM}$ HEPES; $\mathrm{pH}=7.4)$, mixed via end-over-end rotation for $30 \mathrm{~min}$ at $4^{\circ} \mathrm{C}$, sonicated (20\% amplification, 3 cycles), centrifuged $(100,000 \times g$ for $30 \mathrm{~min}$ ), and aliquoted. TBS and SDS buffer aliquots were flash frozen in liquid nitrogen and stored at $-80^{\circ} \mathrm{C}$. Total protein was quantified in TBS and SDS buffer extracts using the Pierce BCA Protein Assay Kit.

\section{Western Blot Analysis}

SDS buffer fractions were analyzed using western blot as described previously (Thomas et al., 2016, 2017; Marottoli et al., 2017, 2019). Briefly, twenty micrograms of protein were separated on $4-12 \%$ Bis-Tris gels (Invitrogen), transferred onto low-fluorescence PVDF membranes, blocked with 5\% milk in TBS for $1 \mathrm{~h}$ at room temperature, washed with $0.1 \%$ Tween20 in TBS (TBS-T), and probed with primary antibodies (see Supplementary Table 1 ) in $1 \%$ bovine serum albumin in TBS with $0.02 \%$ Sodium Azide overnight at $4^{\circ} \mathrm{C}$. After washing $(3 \times 5 \mathrm{~min}$, TBS-T), membranes were incubated for $45 \mathrm{~min}$ in appropriate secondary florescent antibodies (see Supplementary Table 1) in $1 \%$ milk in TBST and $0.01 \%$ SDS. All proteins were imaged and quantified using the Odyssey Fc Imaging System and normalized to GAPDH.

\section{ELISA Analysis}

Apolipoprotein E (ApoE), A $\beta 42$, and Angiotensin II levels were measured in hippocampal homogenates by ELISA. The apoE ELISA was performed using anti-apoE (1:2000, Millipore) and biotinylated anti-apoE (1:5000, Meridian) for capture and detection antibodies as described in Thomas et al. (2016, 2017), Marottoli et al. (2017). A $\beta 42$ (Life Technologies) and Angiotensin II (Cloud-Clone Corp.) were measured following the manufacturer instructions. ApoE, A $\beta 42$, and Angiotensin II levels were normalized to total protein levels in each of the distinct fractions. In addition, we calculated total $\mathrm{A} \beta 42$ and total apoE levels using the following equation:

$$
\frac{(\text { Total A } \beta 42 \text { TBS }+ \text { Total A } \beta 42 \text { SDS buffer })}{\text { (Total Protein TBS }+ \text { Total Protein SDS buffer })}
$$

\section{Cytokine/Chemokine Analysis}

Levels of 31 chemokine/cytokines were quantified in hippocampal homogenates (diluted in Assay Buffer to $0.1 \%$ SDS) using a Mouse cytokine/chemokine magnetic bead panel (MILLIPLEX), following the manufacturer instructions. Concentrations of individual cytokines and chemokines were calculated using Belysa software with a five-parameter logistic curve fitting method, and normalized to total protein levels.

\section{Immunohistochemical Analysis}

Fluorescent IHC analysis was conducted as described previously (Thomas et al., 2016, 2017; Marottoli et al., 2017, 2019). Frozen brains were sectioned at $12 \mu \mathrm{m}$ and nine nonadjacent sagittal sections ( $\sim 108 \mu \mathrm{m}$ apart) were utilized for quantification per animal. Slides were fixed using 10\% Neutral Buffered Formalin (Sigma) for $10 \mathrm{~min}$, washed with PBS $(3 \times 5 \mathrm{~min})$, incubated in $52.8 \%$ formic acid ( $8 \mathrm{~min}$ ), permeabilized for $3 \times 5 \mathrm{~min}$ with PBS containing $0.25 \%$ Triton-X (PBS-X) and blocked with 5\% BSA in PBS-X for $2 \mathrm{~h}$ at room temperature. Slides were then incubated in primary antibody (see Supplementary Table 1) for $48 \mathrm{~h}$ in a humidified chamber at $4^{\circ} \mathrm{C}$ in $\mathrm{PBS}$ containing $2 \%$ BSA and $0.1 \%$ Triton-X. Slides were then washed $(3 \times 5 \mathrm{~min}$ PBS-X), incubated for $2 \mathrm{~h}$ at room temperature with fluorophore-conjugated secondary antibodies in PBS containing $2 \%$ BSA and $0.1 \%$ Triton-X, washed in PBS$\mathrm{X}(3 \times 5 \mathrm{~min})$ and PBS $(1 \times 5 \mathrm{~min})$, and then cover-slipped using Fluoromount-G (SouthernBiotech). Mosaic images were captured and stitched on a Molecular Devices ImageXpress Micro 4 instrument under identical capture settings at $10 \times$ magnification. Quantification was performed using MetaXpress software: images were thresholded to diminish background signal and percent area covered by each stain was calculated in the hippocampus. 


\section{Pharmacokinetic Analysis}

The concentration of candesartan in plasma was evaluated. Standard curves were established in corresponding biological matrix using olmesartan as an internal standard. The standard curve range was $1-1,000 \mathrm{ng} / \mathrm{mL}$. Plasma samples were added to a microcentrifuge tube along with cold acetonitrile containing internal standard. The samples were vortexed, centrifuged and the supernatant was transferred to new tubes for evaporation under nitrogen gas. Once dried down, the samples were reconstituted, vortexed, centrifuged and transferred to LC vial for analysis. Candesartan and olmesartan were monitored using a Shimadzu Ultra-Fast Liquid Chromatograph with Shimadzu 8040 Triple Quadrupole Mass Spectrometer (UFLC-MS/MS). The separation was achieved by using $10 \%$ methanol in water with $0.1 \%$ formic acid and acetonitrile with $0.1 \%$ formic acid as the mobile phases and a Phenomenex Kinetex C18 column $(50 \times 3 \mathrm{~mm}, 2.6 \mu \mathrm{m}$ particles $)$ with the appropriate guard column. The triple quadrupole source was positive electrospray ionization using multiple reaction monitoring to monitor both candesartan and olmesartan. The quantitation analysis was performed using Shimadzu's LabSolutions software, with weighting of the calibration curve model being $1 / \mathrm{x}^{2}$.

\section{Statistical Analysis}

All data are presented as the mean +/- S.E.M and were analyzed using one-way ANOVA followed by Dunnett's multiple comparisons testing, or by using Student's $t$-test with GraphPad Prism version 8.3.1. See Supplementary Table 2 for details on $n$ sizes and statistical comparisons.

\section{RESULTS}

The goal of this study was to evaluate the activity of longerterm candesartan cilexetil treatment at modulating behavior and other markers of AD-relevant pathology in mice that express human APOE4. To address this goal, female (6-10month treatment duration) and male (8-12-month treatment duration) E4FAD - and E4FAD + mice were treated with either vehicle $(0 \mathrm{mg} / \mathrm{kg} /$ day $), 1 \mathrm{mg} / \mathrm{kg} /$ day candesartan cilexetil, or $10 \mathrm{mg} / \mathrm{kg} /$ day candesartan cilexetil in hydrogel. The impact of candesartan cilexetil (referred to as candesartan) treatment on the following was then assessed: plasma drug levels, blood pressure, memory-relevant behavior, synaptic protein levels, angiotensin peptides and receptors, neuroinflammation, $\mathrm{A} \beta$ levels, and cerebrovascular dysfunction (full study design outlined in Supplementary Figure 1).

E4FAD - and E4FAD + mice were selected for this study as they express human APOE4 and exhibit age-related changes in memory-relevant behavior and functions described as potential targets of ARBs (AD-relevant pathology: neuroinflammation, $\mathrm{A} \beta$ levels, and cerebrovascular dysfunction; Youmans et al., 2012; Tai et al., 2017). E4FAD - mice express the human APOE4 gene under the endogenous mouse promoter, and E4FAD+ mice express the human APOE4 gene and overproduce human $\mathrm{A} \beta 42$ through the expression of $5 \mathrm{xFAD}$ autosomal dominant mutations. APOE4 is associated with age-dependent changes in behavior and neuronal function in the absence of high levels of human $\mathrm{A} \beta$ in vivo, including in E4FAD- mice (Wolf et al., 2013; Thomas et al., 2016, 2017; Zaldua et al., 2020). Therefore, E4FAD - and E4FAD + mice were utilized to test whether candesartan modulates functions specific to the interaction of $\mathrm{A} \beta$ and $A P O E 4$ or were generally applicable to APOE4. Previous research in E4FAD - and E4FAD + mice has demonstrated that alterations in behavior and neuronal protein levels occurs earlier in female mice ( $\sim 6$ months) than in male mice ( $\sim 8$ months) (Wolf et al., 2013; Thomas et al., 2016, 2017; Tai et al., 2017; Zaldua et al., 2020). Therefore, candesartan treatments were initiated at different ages for female and male E4FAD mice to try and broadly match AD-relevant pathology at the start of treatment. As our pilot data demonstrated that a $100 \mathrm{mg} / \mathrm{kg} /$ day dose of candesartan produced overt signs of toxicity in mice, a $10 \mathrm{mg} / \mathrm{kg} /$ day dose and a $1 \mathrm{mg} / \mathrm{kg} /$ day dose were selected to assess differences in treatment with a high versus a low dose of the drug. Based on our primary question, statistical analysis was conducted using within group comparisons, i.e., comparing vehicle treatment to candesartan treatment within each genotype for a particular sex (see Supplementary Table 2 for details of statistical analysis).

\section{High-Dose Candesartan Treatment Resulted in Higher Plasma Candesartan Levels and Lower Blood Pressure Compared to Vehicle Treatment in E4FAD - and E4FAD+ Mice}

We initially evaluated the extent that candesartan entered the systemic circulation using plasma pharmacokinetic analysis. Candesartan as the prodrug was administered continuously ad libitum in hydrogel, mimicking an extended-release formulation. In all experimental groups (both female and male, $\mathrm{E} 4 \mathrm{FAD}-$, and $\mathrm{E} 4 \mathrm{FAD}+$ mice), plasma drug levels were greater than $10 \mathrm{ng} / \mathrm{ml}$ in mice treated with $10 \mathrm{mg} / \mathrm{kg} /$ day candesartan (referred to as high-dose; Figure 1A). In mice treated with $1 \mathrm{mg} / \mathrm{kg} /$ day candesartan (referred to as low-dose), drug levels in plasma were variable and in many samples were not above the limit of detection (LOD) of the LC-MS/MS method used. The variance in plasma drug levels in the low-dose candesartan treatment condition may reflect the ad libitum mode of drug-in-hydrogel administration, with some mice consuming hydrogel immediately prior to sacrifice while others did not, which is consistent with the significant, but relatively low concentration measured in the high dose group. The prodrug itself, candesartan cilexetil, was not observed in any samples above its LOD.

An additional method for evaluating plasma drug bioavailability is to assess a peripheral pharmacodynamic readout associated with the drug target. Candesartan was originally developed as a medication to lower blood pressure in patients with hypertension, which may also occur under normotensive conditions. Therefore, we evaluated the effects of candesartan treatment on mean arterial blood pressure in a subset of female and male E4FAD - and E4FAD+ mice at treatment endpoint (Figure 1B). High-dose, but not low-dose, 
A

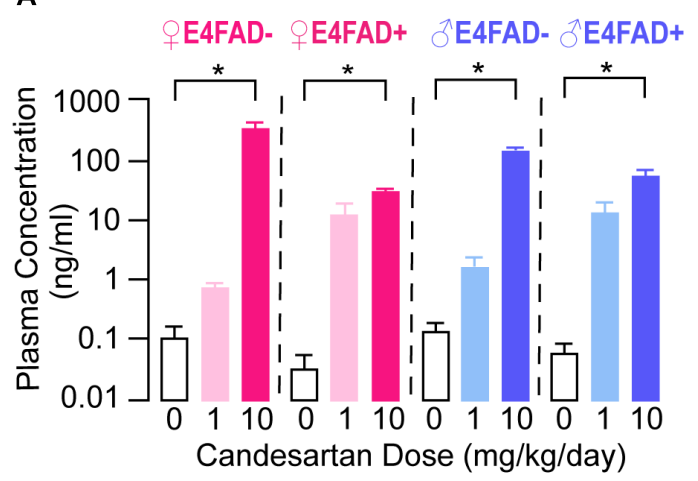

B

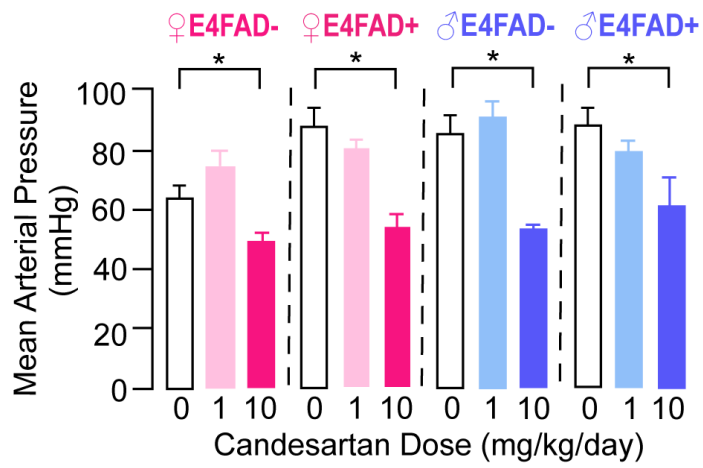

FIGURE 1 | Female and male E4FAD- and E4FAD+ mice treated with high-dose candesartan had higher plasma levels of candesartan and lower blood pressure compared to vehicle. (A) Female and male E4FAD- and E4FAD+ mice treated with $10 \mathrm{mg} / \mathrm{kg} /$ day candesartan (high dose) had higher plasma drug levels than mice treated with vehicle (0 mg/ $\mathrm{kg} /$ day) [Female E4FAD-: $F(2,6)=13.38, p=0.006$. Female E4FAD+: $F(2,5)=19.10, p=0.0046 . \mathrm{Male} E 4 \mathrm{FAD}-: F(2,4)=324.6$, $p<0.0001$. Male E4FAD+: $F(2,6)=13.53, p=0.006]$. (B) Female and male E4FAD- and E4FAD+ mice treated with $10 \mathrm{mg} / \mathrm{kg} / \mathrm{day}$ candesartan had lower mean arterial blood pressure at treatment endpoint compared to vehicle (Female E4FAD-: $F(2,19)=6.54, p=0.0069$. Female E4FAD+: $F(2,22)=11.95, p=0.0003$. Male E4FAD_: $F(2,20)=14.04, p=0.0002$. Male E4FAD+: $F(2,24)=4.56, p=0.021)$. All data expressed as mean $+/-$ SEM. ${ }^{*} p<0.05$ by one-way ANOVA and Dunnet's post-hoc analysis for candesartan dose compared to vehicle. See Supplementary Table 2 for details on $n$ size and statistical comparisons.

candesartan treatment resulted in lower blood pressure in female and male $\mathrm{E} 4 \mathrm{FAD}$ - and $\mathrm{E} 4 \mathrm{FAD}+$ mice compared to vehicle treatment. Indeed, mean arterial pressure was $\sim 15-32 \%$ lower with high-dose candesartan treatment as compared to vehicle treatment. These data suggest that the high-dose treatment of candesartan, resulting in measurable plasma drug levels, induced hypotension in female and male E4FAD - and E4FAD+ mice.

Taken together, our pharmacokinetic and pharmacodynamic data demonstrate that high-dose candesartan treatment, using our treatment regimen, resulted in plasma concentrations in female and male E4FAD - and E4FAD + mice sufficient to elicit an on-target pharmacodynamic effect.

\section{High-Dose Candesartan Treatment Was Beneficial for Memory-Relevant Behavior and Resulted in Higher Hippocampal Synaptic Protein Levels in Female E4FAD- and E4FAD+ Mice}

Impaired memory-relevant behavior with APOE4 has been reported both in the presence and absence of $\mathrm{A} \beta$ in vivo (Thomas et al., 2016, 2017; Zaldua et al., 2020), and data are conflicting on whether ARB treatment considerably modulates memory-relevant behavior in AD-relevant mouse models (Wang et al., 2007; Mogi et al., 2008; Takeda et al., 2009; Tsukuda et al., 2009; Danielyan et al., 2010; Ferrington et al., 2011, 2012; Ongali et al., 2014, 2016; Torika et al., 2016, 2017, 2018; Royea et al., 2017; Trigiani et al., 2018). Therefore, one of our goals was to evaluate whether candesartan treatment could modulate memory-relevant behavior in E4FAD - and E4FAD+ mice. We initially identified that candesartan treatment (lowdose and high-dose) did not alter open field performance. Compared to vehicle treatment, with high-dose candesartan treatment there were no changes in the total distance traveled or percent distance traveled in the perimeter of the open field arena in female and male E4FAD - and E4FAD + mice (Supplementary Figure 2). These data support that candesartan does not alter locomotor activity or anxiety-like behavior in mice that express human APOE4 using our treatment regimen. Next, we evaluated memory-relevant behavior using the novel object recognition test. In female $\mathrm{E} 4 \mathrm{FAD}-$ and $\mathrm{E} 4 \mathrm{FAD}+$ mice, high-dose candesartan treatment resulted in a greater proportion of novel object investigation compared to vehicle treatment. Indeed, in both E4FAD - and E4FAD + female mice treated with high-dose candesartan, performance (preference index) was $\sim 25-30 \%$ higher compared to mice treated with vehicle (Figure 2A, left). In male E4FAD - and E4FAD + mice, highdose candesartan treatment did not modulate performance in the novel object recognition test compared to vehicle treatment (Figure 2A, right).

We next explored whether candesartan treatment altered synaptic protein markers in the hippocampus of E4FADand E4FAD + mice by western blot analysis. Based on novel object recognition data, we only compared high-dose candesartan treatment with vehicle treatment for female and male E4FAD - and E4FAD + mice (i.e., omitted the low-dose candesartan groups). There were no changes in hippocampal levels of archetypal glutamatergic (Vesicular Glutamate Transporter Type 1) or GABAergic (Glutamate Decarboxylase 67) synaptic markers with candesartan treatment in any of the groups (Supplementary Figure 3). However, hippocampal levels of the general presynaptic protein markers synaptophysin, SV2A, and SNAP25 were $\sim 25-40 \%$ higher with high-dose candesartan treatment compared to vehicle treatment in female E4FAD - and E4FAD + mice (Figure 2B, left). In male $\mathrm{E} 4 \mathrm{FAD}-$ and $\mathrm{E} 4 \mathrm{FAD}+$ mice, there were no changes in hippocampal levels of synaptophysin, SV2A, or SNAP25 with candesartan treatment compared to vehicle treatment (Figure 2B, right). Additionally, there were no changes in cortical levels of Vglut1 or synaptophysin in 
A

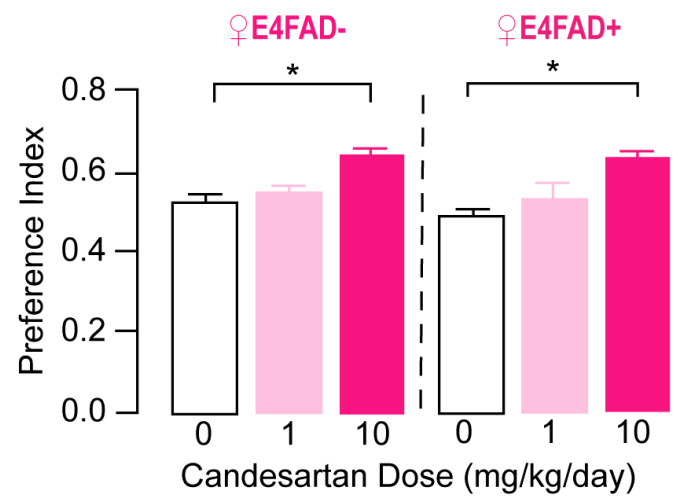

B

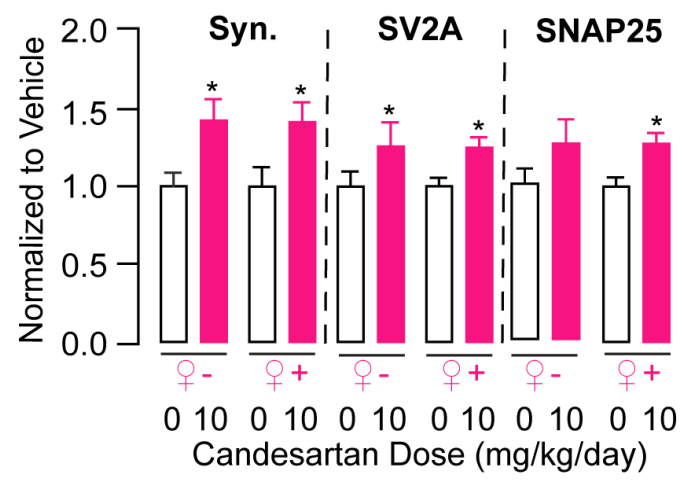

OE4FAD-

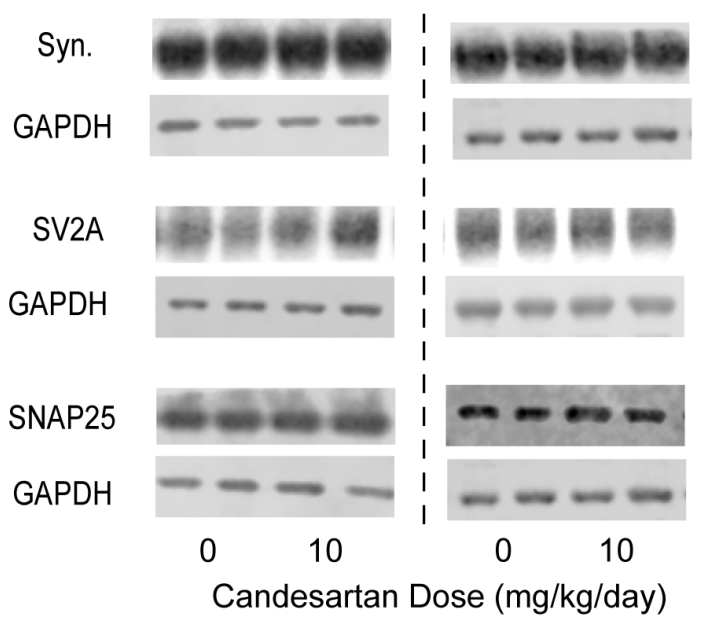

E4FAD-

E4FAD+
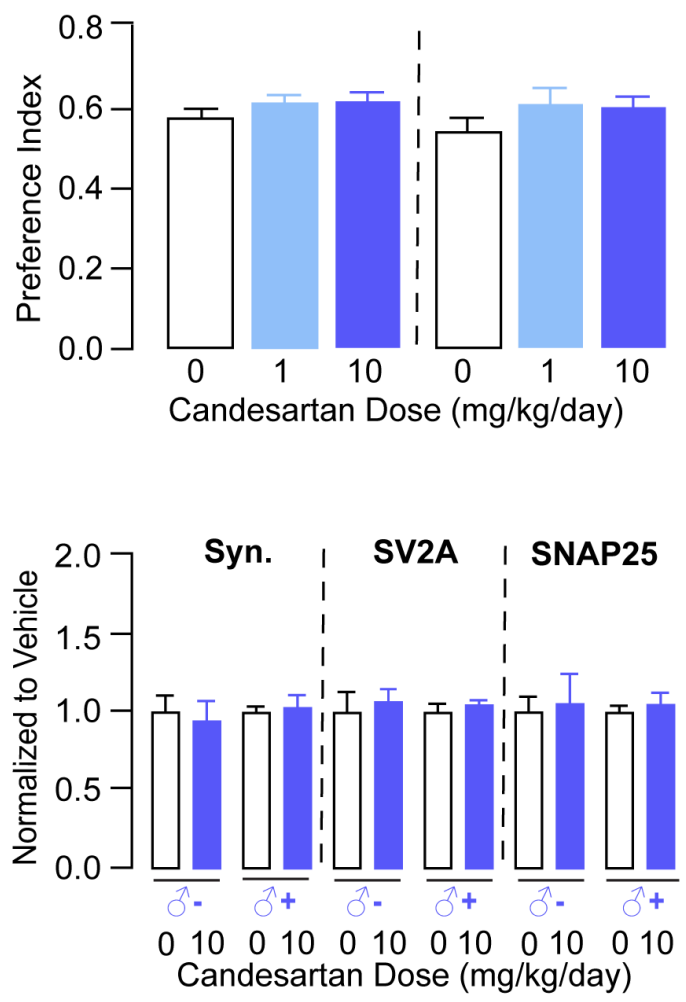

E4FAD-

E4FAD+

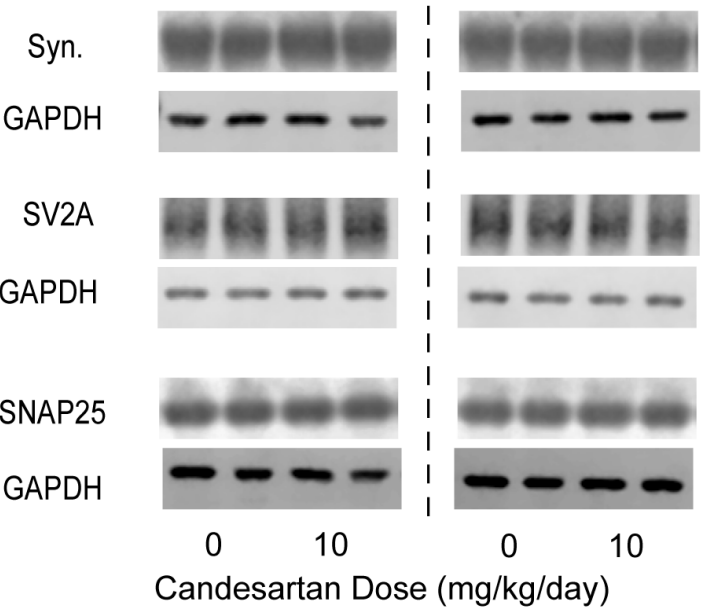

FIGURE 2 | High-dose candesartan treatment resulted in improved memory-relevant behavior and higher hippocampal presynaptic protein levels in female, but not male, E4FAD - and E4FAD + mice. (A) In female E4FAD - and E4FAD+ mice treated with $10 \mathrm{mg} / \mathrm{kg} /$ day (high dose) candesartan, performance was greater in the novel object recognition test compared to vehicle $(0 \mathrm{mg} / \mathrm{kg} /$ day $)$ at treatment endpoint [Female E4FAD-: $F(2,25)=15.29, p<0.0001$. Female E4FAD+: $F(2$, $42)=14.64, p<0.0001]$. This effect was not seen in male E4FAD- and E4FAD+ mice treated with $10 \mathrm{mg} / \mathrm{kg} / \mathrm{day}$ candesartan $[\mathrm{Male} E 4 F A D-: F(2,23)=1.51$, $p=0.24$. Male E4FAD+: $F(2,26)=1.23, p=0.31]$. (B) Female E4FAD - and E4FAD+ mice treated with $10 \mathrm{mg} / \mathrm{kg} / \mathrm{day}$ candesartan had higher hippocampal levels of synaptophysin [Female E4FAD-: $t(17)=2.65, p=0.017$. Female E4FAD+: $t(19)=2.89, p=0.0092]$, SV2A [Female E4FAD-: $t(15)=2.33, p=0.034$. Female E4FAD+: $t(17)=2.83, p=0.012$ ], and SNAP25 [Female E4FAD-: $t(17)=1.45, p=0.16$. Female E4FAD+: $t(20)=3.03, p=0.0067$ ] compared to vehicle when assessed by western blot analysis. Male E4FAD - and E4FAD+ mice treated with $10 \mathrm{mg} / \mathrm{kg} /$ day candesartan did not have altered hippocampal levels of synaptophysin [Male E4FAD-: $t(10)=0.33, p=0.75$. Male E4FAD+: $t(9)=0.34, p=0.74]$, SV2A $[$ Male E4FAD-: $t(10)=0.43, p=0.67$. Male E4FAD+: $t(9)=0.66$, $p=0.53$ ], or SNAP25 [Male E4FAD-: $t(10)=0.25, p=0.81$. Male E4FAD+: $t(9)=0.56, p=0.59$ ] compared to vehicle. Quantification of each protein was normalized to GAPDH as a loading control and all data are expressed as a ratio to vehicle-treated mice. All data expressed as mean $+/-$ SEM. ${ }^{\star} p<0.05$ by one-way ANOVA and Dunnet's post-hoc analysis for candesartan dose comparisons to vehicle (A) and by Student's t-test (B). See Supplementary Table $\mathbf{2}$ for details on $n$ sizes and statistical comparisons. 
female E4FAD+ (Supplementary Figure 6) with high-dose candesartan treatment compared to vehicle treatment. Thus, improvements in memory-relevant behavior associated with high-dose candesartan treatment were accompanied by higher hippocampal presynaptic protein levels in female E4FADand $\mathrm{E} 4 \mathrm{FAD}+$ mice.

\section{High-Dose Candesartan Treatment Did Not Alter Levels of Brain Angiotensin Peptides or Receptors in E4FAD- and E4FAD+ Mice}

We next focused on evaluating markers of pathways that could be associated with/contribute to improvements in memory and synaptic markers with high-dose candesartan treatment in E4FAD - and E4FAD + mice. One possibility was that highdose candesartan altered levels of endogenous brain angiotensin peptides and receptors. Therefore, we began by measuring levels of angiotensin II by ELISA analysis. In female and male E4FADand $\mathrm{E} 4 \mathrm{FAD}+$ mice, there were no differences in hippocampal levels of angiotensin II with high-dose candesartan treatment compared to vehicle treatment (Figure 3A). Consistent with a lack of treatment effect on angiotensin II levels, there were also no differences in hippocampal levels of angiotensinogen, the peptide precursor to angiotensin II, with high-dose candesartan treatment compared to vehicle treatment in female or male E4FAD - and E4FAD + mice when assessed by western blot analysis (Figure 3B). We next assessed whether high-dose candesartan treatment altered angiotensin II receptor levels in the hippocampus of E4FAD - and E4FAD + mice. When assessed by western blot analysis, there were no changes in absolute levels of the AT1 receptor or AT2 receptor with high-dose candesartan treatment compared to vehicle treatment in female or male E4FAD - and E4FAD + mice (Figure 3B). These data collectively support that the beneficial effects of high-dose candesartan treatment in E4FAD - and E4FAD + mice occurred independent of changes in levels of angiotensin peptides or receptors in the hippocampus.

\section{High-Dose Candesartan Treatment Resulted in Lower Levels of Neuroinflammatory Markers in Female E4FAD- and E4FAD+ Mice}

Activation of astrocytes and microglia in the brain, often termed gliosis, are key components of the neuroinflammatory response. One approach to evaluating gliosis is via quantification of staining for Ibal (microglia) and GFAP (astrocytes), levels of which are both higher in AD patients (Hein and O'Banion, 2009) and ARB treatment is associated with lower GFAP and Ibal immunoreactivity in FAD mice (Wang et al., 2007; Mogi et al., 2008; Takeda et al., 2009; Tsukuda et al., 2009; Danielyan et al., 2010; Ferrington et al., 2011, 2012; Ongali et al., 2014, 2016; Torika et al., 2016, 2017, 2018; Royea et al., 2017; Trigiani et al., 2018). Therefore, we measured hippocampal levels of Ibal (Figure 4A) and GFAP (Figure 4B) in female E4FADand $\mathrm{E} 4 \mathrm{FAD}+$ mice by quantitative IHC analysis. Compared to vehicle treatment, with high-dose candesartan treatment there were lower levels of Iba1 (44\% for E4FAD- and 30\% for $\mathrm{E} 4 \mathrm{FAD}+)$ and GFAP (43\%, for E4FAD - and $16 \%$ for $\mathrm{E} 4 \mathrm{FAD}+$ ) in the hippocampus of female E4FAD - and E4FAD + mice. However, there were no differences in cortical levels of GFAP in female E4FAD + mice that were treated with high-dose candesartan compared to vehicle (Supplementary Figure 6B). Alterations in glial morphology is another indication of gliosis (e.g., number of processes in astrocytes, ameboid appearance for microglia); however, qualitatively we could not distinguish the morphology of GFAP-positive astrocytes between candesartantreated and vehicle-treated female E4FAD - and E4FAD + mice (Supplementary Figure 7). Although microglia in E4FAD+ mice appeared more ameboid than E4FAD- mice, most likely due to high $A \beta$ levels, there were no morphological differences in hippocampal Ibal-positive microglia in female E4FADand $\mathrm{E} 4 \mathrm{FAD}+$ mice treated with candesartan compared to vehicle (Supplementary Figure 7). Thus, candesartan treatment potentially modulated the total number of activated astrocytes and microglia, rather than morphology, in the hippocampus. Since candesartan treatment improved behavior and lowered markers of gliosis, we next evaluated whether Ibal or GFAP immunostaining correlated with memory-relevant behavior (NOR preference index) in combined data from female E4FADand E4FAD + mice (Supplementary Figure 5A). In female $\mathrm{E} 4 \mathrm{FAD}-$ and $\mathrm{E} 4 \mathrm{FAD}+$ female mice, there was a moderate negative correlation between hippocampal levels of Iba1, but not GFAP, and NOR performance, (Supplementary Figure 5). One way that glial activation is proposed to modulate neuron function is through the production of cytokines/chemokines; therefore, we measured the levels of 31 chemokines/cytokines in hippocampal SDS extracts of female E4FAD - and E4FAD+ mice (Supplementary Table 3). However, except for GCSF (lower in EFAD+ mice with candesartan treatment compared to vehicle) there were no changes in cytokine/chemokine levels with candesartan treatment. These data suggest that mechanistically, other glial functions are modulated by candesartan treatment to result in improved behavior and neuron function.

Overall, our data demonstrate that compared to vehicle treatment, high-dose candesartan treatment modulated hippocampal astrogliosis and microgliosis in female E4FADand E4FAD + mice, which could contribute to improvements in memory-relevant behavior and synaptic protein levels.

\section{High-Dose Candesartan Treatment Did Not Alter Markers of Vessel Coverage or Cerebrovascular Leakiness in Female E4FAD- and E4FAD+ Mice}

Cerebrovascular dysfunction is generally thought to contribute to neuronal and behavioral dysfunction during $\mathrm{AD}$ progression and is also one of the potential targets of ARB treatment (Wang et al., 2007; Mogi et al., 2008; Takeda et al., 2009; Tsukuda et al., 2009; Danielyan et al., 2010; Ferrington et al., 2011, 2012; Ongali et al., 2014, 2016; Torika et al., 2016, 2017, 2018; Royea et al., 2017; Trigiani et al., 2018). Previous studies have demonstrated lower vessel coverage and higher 
A

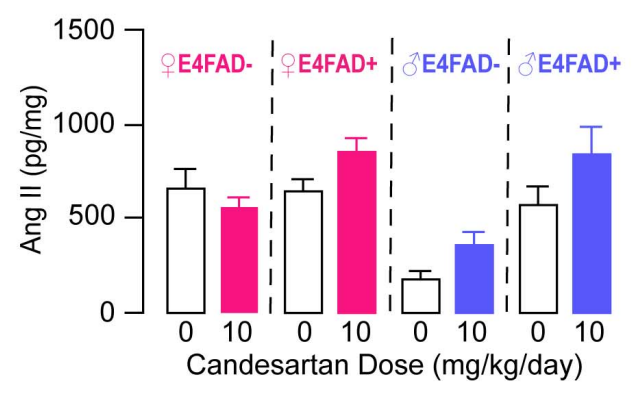

B

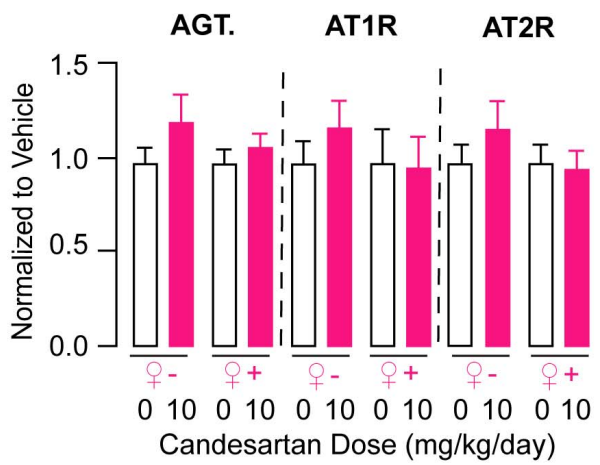

QE4FAD-

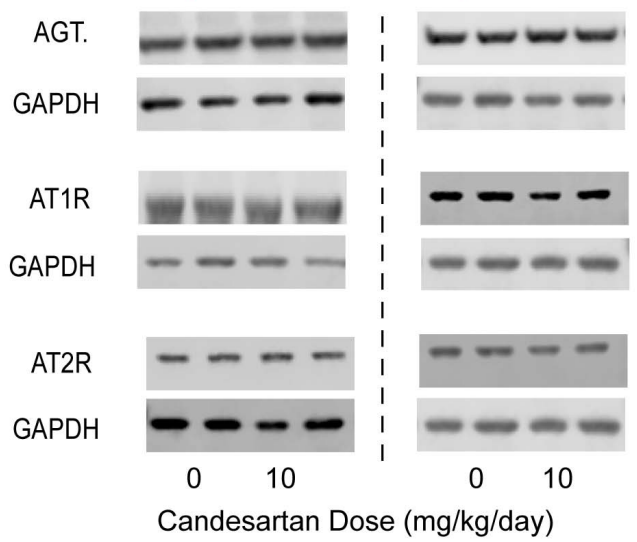

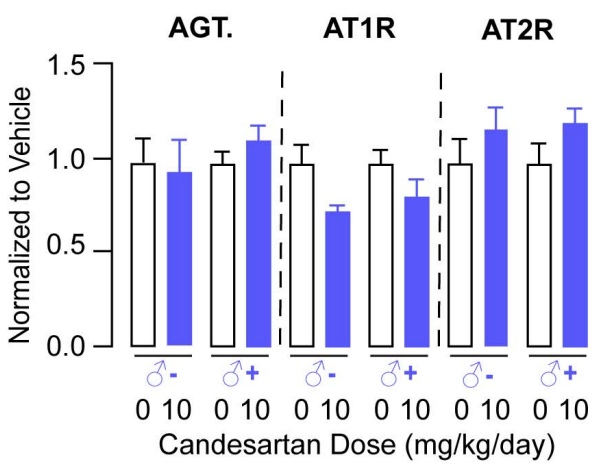

JE4FAD-

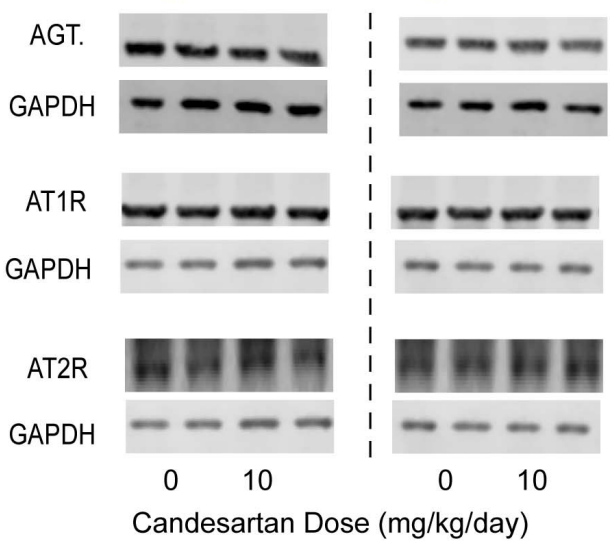

FIGURE 3 | High-dose candesartan treatment did not alter hippocampal angiotensin peptide and receptor levels compared to vehicle treatment in female and male E4FAD - and E4FAD + mice. In female and male E4FAD - and E4FAD+ mice treated with $10 \mathrm{mg} / \mathrm{kg} /$ day candesartan (high dose), there were no differences in hippocampal levels of (A) angiotensin II when assessed by ELISA analysis [Female E4FAD-: $t(18)=0.15, p=0.88$. Female E4FAD+: $t(17)=1.85, p>0.081$. Male E4FAD-: $t(8)=2.23, p=0.056$. Male E4FAD $+: t(8)=1.53, p=0.16$ ] as well as $(\mathbf{B})$ angiotensinogen, AT1 receptor, or AT2 receptor levels compared to vehicle when assessed by western blot analysis [Angiotensinogen: Female E4FAD-: $t(17)=1.30, p=0.21$. Female E4FAD $+: t(22)=0.81, p=0.43$. Male E4FAD-: $t(10)=0.27$, $p=0.79$. Male E4FAD $+: t(9)=1.19, p=0.26$. AT1: Female E4FAD-: $t(18)=1.00, p=0.33$. Female E4FAD $+: t(21)=0.09, p=0.92$. Male E4FAD-: $t(10)=2.28$, $p=0.073$. Male E4FAD $+: t(9)=1.44, p=0.18$. AT2: Female E4FAD $-: t(18)=1.00, p=0.33$. Female E4FAD $+: t(22)=0.21, p=0.84$. Male E4FAD-: $t(10)=1.04$, $p=0.32$. Male E4FAD+: $t(9)=1.45, p=0.17]$. In (B) quantification of each protein was normalized to GAPDH as a loading control and all data are expressed as a ratio to vehicle-treated mice. All data expressed as mean $+/-$ SEM. $p>0.05$ by Student's $t$-test. See Supplementary Table 2 for details on $n$ sizes.

cerebrovascular leakiness in 8 month old E4FAD- (Thomas et al., 2017) and E4FAD+ mice (Tai et al., 2017) compared to mice expressing APOE3. Therefore, we assessed whether highdose candesartan treatment in female E4FAD - and E4FAD+ mice modulated these markers of cerebrovascular dysfunction using quantitative IHC analysis.
Vessel coverage was measured by staining for the endothelial cell marker CD31, and vascular leakiness was measured by staining for the plasma protein fibrinogen, which does not normally cross an intact cerebrovasculature. There were no differences in CD31 (Figure 5A) or fibrinogen (Figure 5B) staining in the hippocampus of 
A

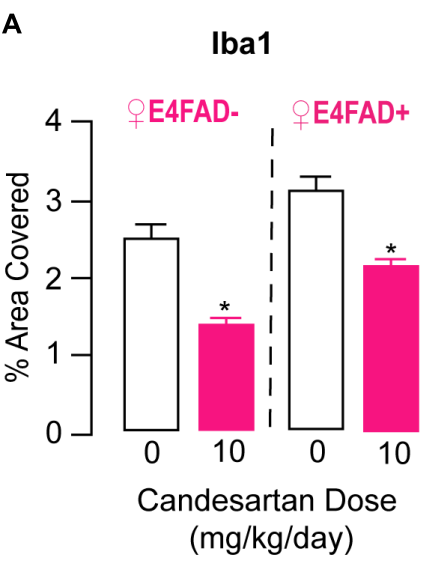

B

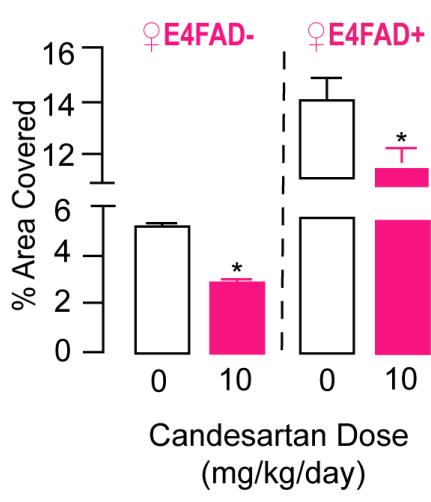

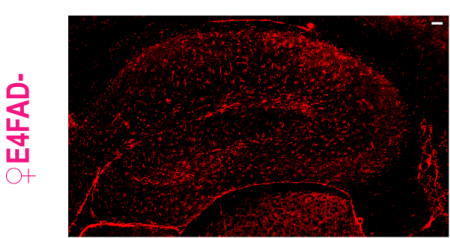
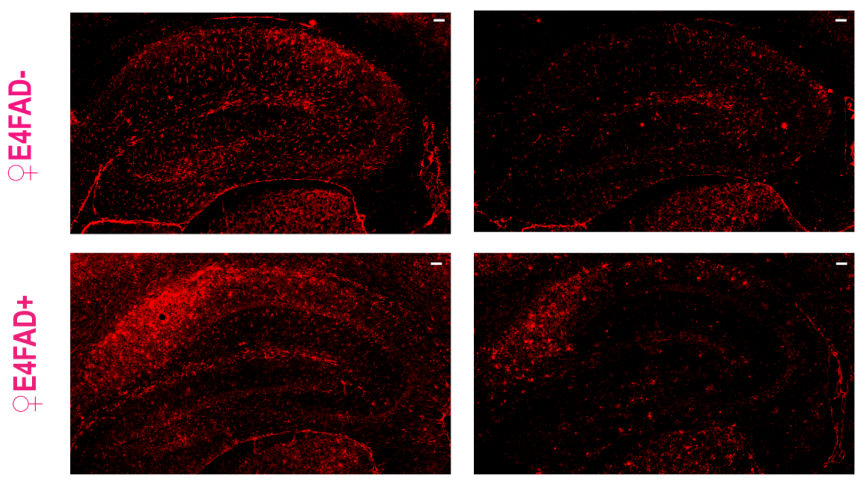

0

Candesartan Dose

10

( $\mathrm{mg} / \mathrm{kg} /$ day)
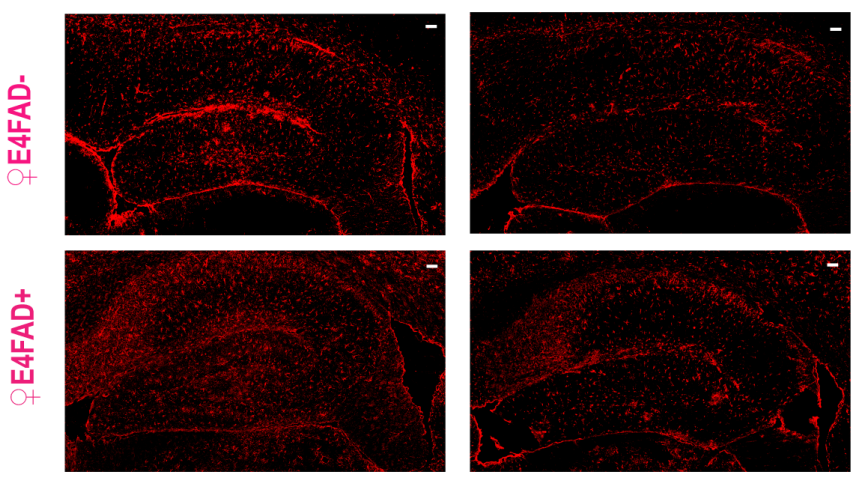

0

Candesartan Dose

10 (mg/kg/day)

FIGURE 4 | High-dose candesartan treatment resulted in lower hippocampal levels of neuroinflammatory markers compared to vehicle treatment in female E4FAD_ and E4FAD+ mice. Female E4FAD - and E4FAD+ mice treated with $10 \mathrm{mg} / \mathrm{kg} /$ day (high dose) candesartan had a lower percentage of hippocampal area immunostained with (A) Iba1 [E4FAD-: $t(16)=6.76, p<0.0001$. E4FAD+: $t(18)=5.08, p<0.0001]$ and (B) GFAP [E4FAD-: $t(16)=15.06, p<0.0001$. E4FAD+: $t(18)=2.44, p=0.025]$ compared to vehicle $\left(0 \mathrm{mg} / \mathrm{kg} /\right.$ day) when assessed by quantitative $\mathrm{IHC}$ analysis. All data expressed as mean $+/-\mathrm{SEM}$. ${ }^{\star} p<0.05$ by Student's $t$-test. Scale bars $=100 \mu \mathrm{m}$. See Supplementary Table 2 for details on $n$ sizes

female E4FAD - and E4FAD + mice treated with highdose candesartan compared to vehicle, indicating that the beneficial effects of high-dose candesartan treatment, using our treatment regime, occurred independently of effects on the cerebrovasculature.

\section{High-Dose Candesartan Treatment Did Not Alter $A \beta$ or apoE Levels in Female E4FAD- and E4FAD+ Mice}

.5In published studies there is no clear consensus on whether $\mathrm{ARB}$ treatment impacts $\mathrm{A} \beta$ levels in FAD mice (Wang et al., 2007; Mogi et al., 2008; Takeda et al., 2009; Tsukuda et al., 2009; Danielyan et al., 2010; Ferrington et al., 2011, 2012; Ongali et al., 2014, 2016; Torika et al., 2016, 2017, 2018; Royea et al., 2017; Trigiani et al., 2018). Our data demonstrates that high-dose candesartan treatment was beneficial for memory-relevant behavior, synaptic protein markers, and neuroinflammation in both E4FAD - and E4FAD + female mice, findings that suggest that these improvements occurred independent of high $\mathrm{A} \beta$ levels. However, it was important to assess whether the beneficial effects seen with our treatment design were accompanied by lower $\mathrm{A} \beta$ pathology in $\mathrm{E} 4 \mathrm{FAD}+$ mice. Therefore, extracellular $A \beta$ deposits were measured by immunostaining with the anti-A $\beta$ antibody MOAB-2. No alterations in hippocampal MOAB-2 levels were observed in female $\mathrm{E} 4 \mathrm{FAD}+$ mice treated with high-dose candesartan compared to vehicle (Figure 5C). To follow up on this finding, we quantified levels of soluble $\mathrm{A} \beta 42$ and total $\mathrm{A} \beta 42$ levels by ELISA analysis, since $\mathrm{A} \beta 42$ is considered a particularly detrimental form of A $\beta$ (Qiu et al., 2015). There were no differences in hippocampal levels of soluble $A \beta 42$ (Supplementary Figure 4A) or total A $\beta 42$ (Supplementary Figure 4B) in female E4FAD+ mice that were treated with high-dose candesartan compared to vehicle. In addition, in the hippocampus of both female E4FAD - and E4FAD + mice there 
A

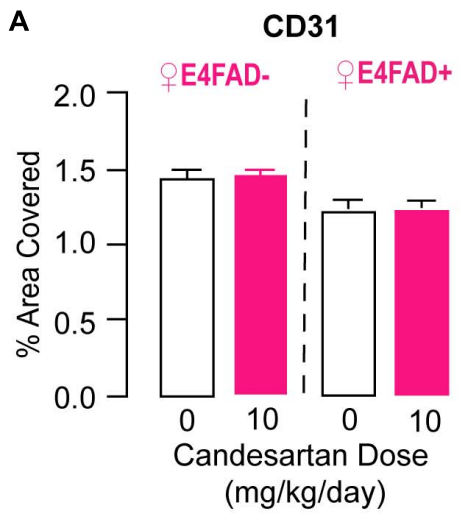

B

Fibrinogen

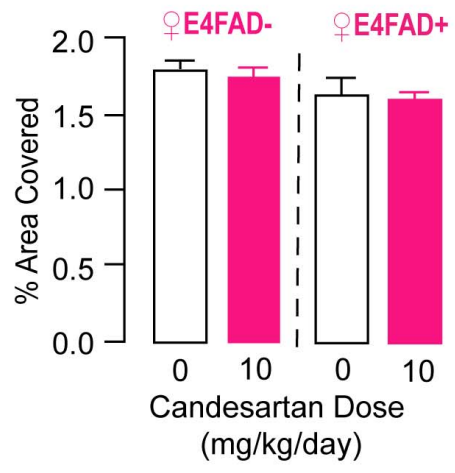

C

\section{Extracellular $A \beta$}

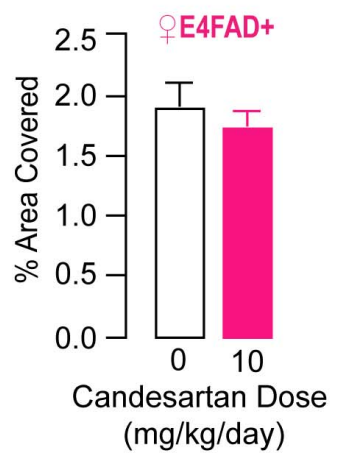

OEAFAD-
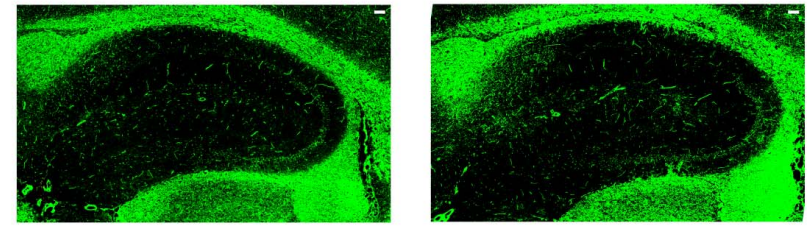

OE4FAD+

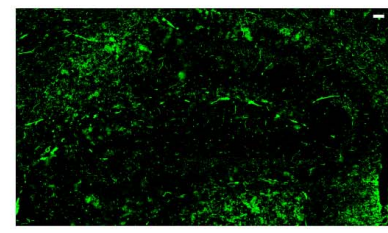

0

Candesartan Dose

( $\mathrm{mg} / \mathrm{kg} /$ day)
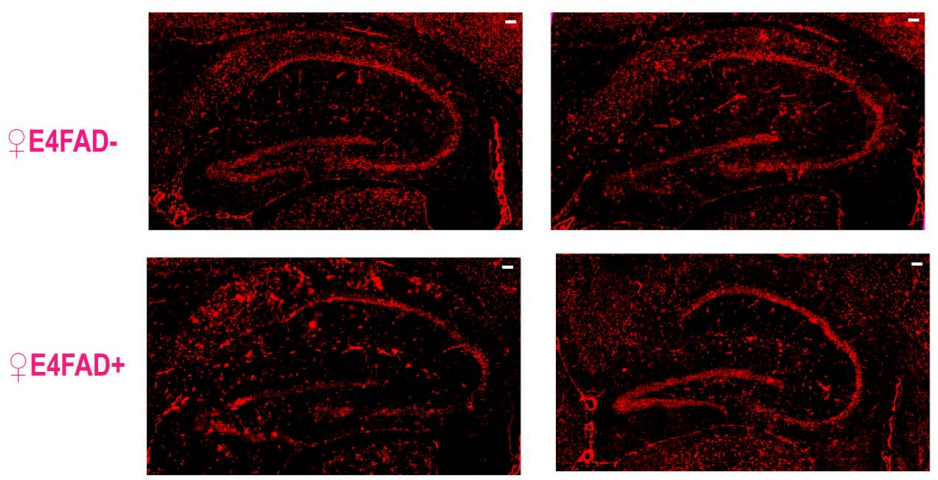

0

$$
\begin{gathered}
\text { Candesartan Dose } \\
\text { (mg/kg/day) }
\end{gathered}
$$

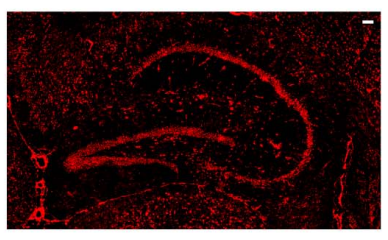

10

\section{0}

10

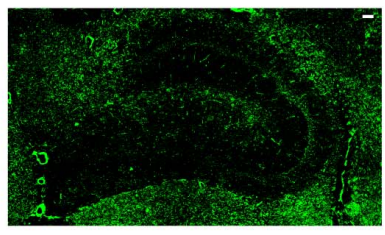

\section{(1)}




\section{DISCUSSION}

In this study we have demonstrated that systemic treatment with candesartan cilexetil results in improved short-term memory, higher synaptic protein levels, and modulated neuroinflammatory markers in female mice, but not male mice, that express the human APOE4 gene. These data support further research on the role of the AT1 receptor in modulating neuroinflammation and neuronal function from mechanistic and therapeutic perspectives.

\section{Clinical and in vivo AD Relevance for the Modulation of Behavior by ARB Treatment}

Prospective cohort analyses and observational studies support that ARBs could limit the detrimental effects of hypertension on AD risk and progression (Tzourio, 2007; Li et al., 2010; Davies et al., 2011; Kume et al., 2012; Ho et al., 2017). For example, the use of ARBs is associated with lower risk of developing $\mathrm{AD}$ ( $\mathrm{Li}$ et al., 2010), slower cognitive decline (Kume et al., 2012), and improvements in short- and longterm memory preservation in $\mathrm{AD}$ patients (Ho et al., 2017); however, there are some contrasting data (Hsu et al., 2013; Kurinami et al., 2013). Underlying the conflictions in human data could be the age of hypertension onset in $\mathrm{AD}$ patients. Indeed, increasing evidence supports that hypertension in mid-life is particularly harmful for $\mathrm{AD}$ risk and progression, and therefore ARB treatment should be administered early (Launer et al., 2000). Importantly, through these initial studies a key concept emerged: that ARBs could modulate AD-relevant pathology independent of hypertension. Human evidence for this concept is that ARB use, as compared to the use of other classes of antihypertensive medications such as ACE inhibitors and Betablockers, is associated with lower neuritic plaque count and a reduction in neurofibrillary tangles in $\mathrm{AD}$ patient brain tissue (Hoffman et al., 2009; Hajjar et al., 2012). In addition, the AT1 receptor is expressed in brain regions relevant to learning, memory, and $\mathrm{AD}$ (e.g., hippocampus and cerebral cortex) in mice (Allen et al., 1998), rats (Lenkei et al., 1997), gerbils (Tonelli et al., 2000), dogs (Speth et al., 1985), and humans (MacGregor et al., 1995). Further, higher levels of AT1 receptor activation can result in memory impairment and neuronal dysfunction (Benicky et al., 2009; Saavedra, 2012a,b, 2016). The collective evidence that AT1 receptor activation could contribute to changes in learning, memory, and synaptic biology relavent for $\mathrm{AD}$, led to an evaluation of $\mathrm{ARB}$ activity in $\mathrm{AD}$-relevant rodent models. Most of these studies support that ARB treatment is beneficial for memory-relevant behavior and markers of neuronal function in FAD mouse models that overexpress human A $\beta$. For instance, telmisartan (Mogi et al., 2008; Tsukuda et al., 2009; Torika et al., 2017) losartan (Danielyan et al., 2010; Ongali et al., 2014; Royea et al., 2017), valsartan (Wang et al., 2007), and candesartan (Trigiani et al., 2018) treatment resulted in improvements in learning and memory-type behavior in various FAD mouse models (e.g., APP/PS1, J20, and 5xFAD). Further, olmesartan treatment reversed deficits in hippocampal LTP in A $\beta$-injected mice (Takeda et al., 2009), candesartan treatment resulted in higher dendritic arboriztion in J20 mice (Trigiani et al., 2018), and losartan treatment resulted in higher tyrosine hydroxylase expression in APP/PS1 mice (Danielyan et al., 2010). To date, eprosartan is the only $\mathrm{ARB}$ tested that appeas not to modulate memory-relevant behavior in 3xTG AD mice (Ferrington et al., 2012) and in APP/PS1 mice (Wiesmann et al., 2017). However, this could be because eprosartan has lower bioavailability and potency than other clinically used AT1 receptor antagonists, and therefore could require higher doses for biological activity in FAD mice (Michel et al., 2013). Further, the choice of prodrug (candesartan cilexetil) used also impacts drug pharmacokinetics and pharmacodynamics. Our data are in agreement with and expand upon reports indicating beneficial effects of ARBs on memory and markers of neuronal function in $\mathrm{AD}$-relevant rodent models. In our current study, candesartan improved memoryrelevant behavior and presynaptic protein levels in mice in the context of two key AD risk factors: female sex and APOE4 (see below for detailed discussion). Therefore, collectively there is a growing body of human and in vivo evidence supporting that ARBs may have therapeutic value in AD.

\section{Inflammatory Processes Modulated by ARB Treatment}

Key for the full evaluation of ARBs as an AD therapy is understanding their cellular mechanism(s) of action. Although precise mechanisms cannot be identified with our study design, our data on changes in AD-relevant pathology could help guide future mechanistic research on this topic. There are a number of potential explanations for our data, however, we would like to initially focus on a speculative mechanism of action whereby candesartan blocks the AT1 receptor on astrocytes or microglia, resulting in altered cellular phenotypes that are beneficial and/or less detrimental for neuronal function and behavior. This proposed mechanism raises important points regarding candesartan brain bioavailability, angiotensin II and AT1 receptor levels/expression and functions in the brain, and neuroinflammatory phenotypes linked to neuron function.

Angiotensin receptor blockers were originally developed for the treatment of hypertension, and therefore no pharmacokinetic studies directly centered on brain bioavailability have been conducted, which is also a limitation of our study (see "limitations" section below). However, there is indirect evidence that candesartan can cross the blood-brain barrier following peripheral administration. Candesartan when administered via osmotic minipumps at $0.1,0.5$, and $1.0 \mathrm{mg} / \mathrm{kg} /$ day inhibited AT1 receptors in the brain when assessed by autoradiography studies in wild type rats (Nishimura et al., 2000). Similarly, candesartan administered via i.v. at doses of $0.01,0.1,1$, or $10 \mathrm{mg} / \mathrm{kg} /$ day blocked angiotensin II-induced (i.c.v.) drinking and pressor responses in rats (Gohlke et al., 2002). Thus, candesartan may be brain penetrant in wild type rodents when administered peripherally, and data also suggests that this is the case for AD-relevant rodent models. When administered in drinking water at a dose of $10 \mathrm{mg} / \mathrm{kg} / \mathrm{day}$, candesartan modulated neuroinflammation and hippocampal dendritic arborization in 
J20 mice (Trigiani et al., 2018). In general, there are a number of properties that determine the extent that a drug is brain penetrant from both a chemical and biological perspective. Two important biological aspects relate to the specialized functions of the blood-brain barrier: low paracellular permeability and high expression of efflux transporters. Regarding the former, research, including our own (Tai et al., 2017), has demonstrated that there is higher paracellular permeability and blood-brain barrier breakdown in mice that express APOE4 at the ages used in this study. Further, although the AT1 receptor is expressed on brain endothelial cells and excessive AT1 receptor signaling has been shown to directly impair endothelial cell function (FleegalDeMotta et al., 2009), in our study candesartan treatment did not result in changes to vascular permeability (fibrinogen) in female E4FAD - and E4FAD+ mice. Therefore, blood-brain barrier dysfunction may be too far advanced in E4FAD mice at the ages evaluated in this study (Thomas et al., 2016, 2017; Zaldua et al., 2020) for candesartan to have exerted a beneficial effect, or the contribution of the AT1 receptor to cerebrovascular dysfunction is minimal in E4FAD mice. For either event, the result may be that a disrupted blood-brain barrier in E4FAD mice enabled candesartan to cross into the brain. Future studies focused on detailed pharmacokinetic analysis of candesartan are important for a mechanistic interpretation of how systemic treatment improved behavioral function in female APOE4 mice.

Once inside the brain our working hypothesis is that candesartan prevents angiotensin II from activating AT1 receptors on glia, which raises the important discussion points of the source and levels of angiotensin II in the brain under normal and pathological conditions, if glia respond to angiotensin II, and whether blocking the AT1 receptor modulates neuroinflammation. One way that angiotensin II could enter the brain is by crossing in from the periphery through receptor mediated transport, diffusion, and/or at the circumventricular organs. Alternatively, there may be local production and it has been proposed that cells within the brain collectively express proteins and enzymes to enable angiotensin II production (McKinley et al., 2003; Sakai et al., 2007). For either scenario, the physiological functions of angiotensin II in the brain, and specifically in the hippocampus, are unclear, but could relate to communicating blood-pressure responses from the periphery to the brain, or an adaptation of angiotensin II to act as a local homeostatic signaling molecule related to inflammatory or stress stimuli. During aging, with APOE4, female sex, and/or $\mathrm{A} \beta$ pathology the amount of angiotensin II may be modulated in the brain to levels that become detrimental. For example, a disrupted cerebrovasculature would enable higher peripheral entry of angiotensin II, and local brain production could also increase in response to aging and $\mathrm{AD}$-relevant stressors. Thus, although in the current study we found no change in angiotensin II levels with candesartan treatment in female E4FAD- or E4FAD + mice, the possibility remains that angiotensin II levels increase with aging to activate glia. Alternatively, rather than levels of angiotensin II, in female E4FAD- and E4FAD + mice there may be a synergistic interaction between AT1 receptor signaling and other signaling pathways modulated by APOE4 and female sex in glia. Like angiotensin II, the extent that the expression of the AT1 receptor is regulated in the brain is unclear. In our study there were no differences in levels of the AT1 receptor in hippocampal brain homogenates between vehicle and candesartan-treated mice, but the way that we collected tissue for IHC analysis precluded cell-type specific evaluation of AT1 receptor expression and levels (non-fixed perfused). However, in general, other research groups have identified that glia express the AT1 receptor, that glial AT1 receptors respond to angiotensin II, and/or that blocking the AT1 receptor in glia modulates inflammation. In astrocytes, AT1 receptor expression has been confirmed by quantitative IHC analysis in adult wild type rats (Fogarty and Matute, 2001) and mouse models of multiple sclerosis (Lanz et al., 2010). In addition, angiotensin II treatment of astrocytes results in superoxide production and senescence (Liu et al., 2011), and data from in vivo lesion studies support that AT1 receptor activation in astrocytes promotes a neuroinflammatory phenotype (Fuchtbauer et al., 2011). Studies have also demonstrated that microglia express the AT1 receptor in the cerebral cortex of adult rats (Wu et al., 2013) and mice (Phipps et al., 2018; Cui et al., 2019), angiotensin II activates microglia in vitro (Villar-Cheda et al., 2012), and blocking microglial AT1 receptor suppresses their activation in response to inflammatory stimuli (Benicky et al., 2011; Sun et al., 2015). Further, ARB treatment of FAD rodent models lowers markers of astrocyte and microglia activation as we found in E4FAD mice (Danielyan et al., 2010; Ongali et al., 2014; Torika et al., 2016; Royea et al., 2017; Torika et al., 2017, 2018; Trigiani et al., 2018). There are many questions remaining surrounding the levels and functions of angiotensin II and glial expressed AT1 receptors in physiological and pathological states (see "limitations" section). However, the studies described above suggest that glia express the AT1 receptor which, when activated, modulates inflammatory responses. Thus, it is possible that during aging, $\mathrm{AD}$-relevant risk factors and stressors (e.g., APOE4, $\mathrm{A} \beta$ ) disrupt normal homeostatic functions of AT1 receptor signaling in glia, which underlies the mechanisms of how ARB treatment improves behavior.

The general concept that blocking the AT1 receptor on glia can alter their activation states, raises the more specific question of how this resulted in improved behavior with candesartan treatment. Although hippocampal levels of Ibal, but not GFAP, correlated with improvements in memory-relevant behavior in female E4FAD mice, there are limitations in this type of analysis (e.g., assumptions in linearity, read-out specificity, and lack of longitudinal analysis). Therefore, we will discuss in more detail ways that blocking the AT1 receptor in astrocytes or microglia could have improved neuronal function in female E4FAD mice. Astrocytes perform multiple functions to maintain homeostasis of the central nervous system including buffering potassium ions, recycling neurotransmitters, regulating homeostasis of lactate/glucose, buffering $\mathrm{pH}$, aiding interstitial fluid bulk flow, secreting protective molecules for neurons and the vasculature, as well as modulating cytokine and chemokine production. The idea that any of these astrocytic functions are disrupted in $\mathrm{AD}$ or FAD mice was initially based on GFAP staining, as when activated the levels of GFAP (intermediate filaments prominent in processes) are higher in astrocytes. In FAD models and $\mathrm{AD}$ 
human postmortem tissue, GFAP immunostaining is higher than wild-type or age-matched controls, respectively, particularly surrounding $\mathrm{A} \beta$ extracellular deposits and neurofibrillary tangles of tau (Simpson et al., 2010; Verkhratsky et al., 2010). APOE4 is also associated with higher GFAP levels in FAD mice and in response to inflammatory stress (Zhu et al., 2012; Fernandez et al., 2019). The higher GFAP immunoreactivity in ADrelevant contexts likely represents the amount of astrocytes that have become active, rather than a change in absolute numbers or migration. Thus, GFAP in many ways is a surrogate marker for astrocytic phenotypes, but the link to functional consequences is less clear and becoming increasingly complicated. Indeed, single cell gene expression and transcription analysis studies continue to identify several different astrocytic phenotypes including A1/A2, disease associated (Habib et al., 2020), proinflammatory, neurotoxic, as well as associated sub-sets (reviewed in Spanos and Liddelow, 2020). In many cases the gene profiles across studies at least partially overlap, and more research is required to synergize nomenclature across studies and identify the functions of different astrocytic phenotypes. Nonetheless, there is an apparent consensus across the transcriptomic studies that in a chronic condition such as $\mathrm{AD}$, it is important for astrocytes to modulate inflammatory phenotypes (i.e., prevention of neurotoxicity induced by cytokines) while promoting homeostatic functions [neuroprotective functions described above (Spanos and Liddelow, 2020)], which may have been the case in candesartan-treated female E4FAD mice. Hopefully more specific and tangible concepts will evolve as studies on astrocyte biology begin to incorporate how treatments modify their transcriptomics phenotypes. Like astrocytes, the functions of microglia in the brain are complex and they exist as a heterogenous phenotype. In general, the functions of microglia include phagocytosis of apoptotic cells, pathogens, $A \beta$, and synapses/synaptic pruning, and secretion of cytokines/chemokines or protective factors. In FAD mice and $\mathrm{AD}$ patients, there are higher numbers of Iba1-positive cells, which likely represents migration of microglia to the area, or potentially infiltration and differentiation of peripheral immune cells (Hein and O'Banion, 2009; Balducci et al., 2018; Toscano et al., 2020). In addition to number, the activation of microglia is associated with a morphological shift in appearance from small cell somas and long processes to large cell bodies with fewer and shorter processes (Schlachetzki and Hull, 2009). Qualitatively we did not observe any differences in the morphology of microglia with candesartan treatment in E4FAD mice, and therefore it is the number of activated microglia that was likely modulated by candesartan treatment. However, a lack of morphological change in glial cells does not necessarily imply a lack of an impact on phenotypes. Indeed, single cell transcriptomic analysis has identified different types of microglial phenotypes in FAD mice (Keren-Shaul et al., 2017; Habib et al., 2020), in neurodegenerative disorders, and it has also been proposed that $A P O E$ genotype modulates microglial phenotypes. However, when identified by gene expression profiling, whether a disease associated microglial phenotype is beneficial or detrimental for neuronal function is still subject for debate. For example, APOE4 has been proposed to be associated with a disease associated transcriptomic phenotype, which functionally may manifest as higher cytokine production, impaired migration, and lower phagocytosis (Fernandez et al., 2019). At the same time, other gene expression profiles described as disease associated are interpreted as beneficial. For example, it has been suggested that unblocking microglial specific check points to enrich subsets of disease associated microglia is optimal for promoting neuron function (Keren-Shaul et al., 2017). In our study, we saw lower Ibal staining with candesartan treatment and no change in $\mathrm{A} \beta$ levels, which would be characteristic of a beneficial phagocytotic phenotype. Therefore, our data suggest that ARBs lowered the amount of activated microglia, consistent with other ARB treatment studies in FAD mice (Danielyan et al., 2010; Ongali et al., 2014; Torika et al., 2016, 2017, 2018; Royea et al., 2017; Trigiani et al., 2018), although it is possible the remaining microglia were of a beneficial phenotype. Overall, astrocytes and microglia are linked to multiple functions that could have been modulated by ARB treatment in female E4FAD - and E4FAD + mice. Traditionally, shifting cytokine and chemokine levels/phenotypes has been considered the major beneficial consequence of lower GFAP and/or Iba1 levels. However, candesartan treatment did not result in changes in levels of many common cytokines/chemokines in the hippocampus of female E4FAD - or E4FAD + mice. There are caveats to these data including: for cytokines/chemokine levels the effect of candesartan could be acute (i.e., influenced by amount of drug onboard at time of sacrifice), cytokines/chemokines that we did not measure were altered, and/or there were hippocampal sub-region differences in cytokine/chemokine levels. Yet, our data may be more consistent with the idea that candesartan modulated other glial functions in order to improve neuron function, such as homeostatic regulation of potassium ions, neurotransmitters, and energy supply, secretion of neuroprotective factors, and surveillance/phagocytosis. Future studies using single-cell transcriptomics analysis could reveal the extent that candesartan alters astrocytic and microglial phenotypes in E4FAD mice, which combined with proteomics and functional assays for neurons, could reveal more detailed mechanisms of how AT1 receptor activation in glia impacts neuron function and behavior.

Neuroinflammation is a complex and at times abstract concept that refers to activation states and phenotypes of multiple cell types (astrocytes, microglia, pericytes, endothelial cells, neurons, and peripheral immune cells). In the context of our study, we found changes in the levels of astrocytes and microglia, however, there are alternative hypotheses for how candesartan could have improved behavior and neuroinflammation in our study. Candesartan may have improved behavior in APOE4 mice through directly lowering AT1 receptor activation in neurons (Sandgren et al., 2018). Indeed, angiotensin II has been demonstrated to modulate synaptic proteins levels in vitro (Kurihara et al., 2008) and regulate neuronal firing rates (Li et al., 2003; Li and Pan, 2005) and membrane ionic currents when assessed using electrophysiological analysis (Sumners et al., 1996; Wang et al., 1997). In addition, blocking AT1 receptor signaling on neurons could have also lowered glial activation (Elsaafien et al., 2020) which in turn reduces neuronal 
dysfunction. Alternatively, the beneficial effects of ARBs on behavior could be mediated through modulation of inflammatory processes related to AT1 receptor signaling in the periphery. The AT1 receptor is expressed by multiple cell types related to control of peripheral inflammation (e.g., macrophages) and blood pressure (e.g., smooth muscle cells, endothelial cells; Villapol and Saavedra, 2015). Often these two processes are considered linked, since ARB treatment has general anti-inflammatory properties in both humans with hypertension (Fliser et al., 2004) and in vivo (Marchesi et al., 2008). However, recent studies support that ARBs can alter peripheral inflammation independent of blood pressure-lowering effects in hypertension (Pang et al., 2012; Villapol and Saavedra, 2015). Peripheral inflammation, such as changes in cytokine and chemokine levels as well as activated immune cells, is linked to AD-relevant pathology and behavior in AD-relevant mouse models including with APOE4 (Benicky et al., 2009; Marottoli et al., 2017). Indeed, with APOE4 there is an altered inflammatory response in both humans and mice treated with inflammatory stressors (Gale et al., 2014; Tai et al., 2015). Therefore, one potential explanation for our data is that ARBs modulated peripheral inflammation to improve behavior and synaptic function. However, altering peripheral inflammation in vivo is typically associated with improvements in cerebrovascular function, which we did not observe in this study. An additional explanation is that there is a connection between the lower blood pressure in female E4FAD - and E4FAD+ mice after ARB treatment and improved behavioral function. A link between lowering blood pressure in non-hypertensive mice and improved memory has not been established, and we observed lower blood pressure in male E4FAD mice without an associated improvement in behavior. Further, previous studies evaluating the activity of ARBs in FAD mice have found similar memory-improving benefits in the absence of any changes to systemic blood pressure (Wang et al., 2007; Mogi et al., 2008; Danielyan et al., 2010; Ongali et al., 2014; Royea et al., 2017), suggesting that ARBs modulate learning and memory-type behavior independent of blood pressure. Inducing hypotension in a non-hypertensive $\mathrm{AD}$ patient is also likely to be considered a detrimental side effect. In addition, APOE4 is associated with several other peripheral changes such as alterations in metabolism, and the gut microbiome, any of which could have been modulated by ARB treatment (Gregg et al., 1986; Bandaru et al., 2009; Maldonado Weng et al., 2019; Parikh et al., 2020). Taken together, further research could aid in evaluating the extent that the AT1 receptor in the periphery modulates inflammation in AD-relevant contexts and the development of novel ARBs that display higher brain penetration could limit clinical hypotensive effects of ARBs.

\section{Role of $A P O E 4$, Female Sex, and $A \beta$ in Contributing to ARB Activity}

Our study raised several important discussion points: that candesartan benefited memory-relevant behavior in female, but not male, mice expressing APOE4, that these benefits occurred both in the presence $(\mathrm{E} 4 \mathrm{FAD}+)$ and absence $(\mathrm{E} 4 \mathrm{FAD}-)$ of $\mathrm{A} \beta$ overproduction, and that beneficial effects on behavior with candesartan treatment coincided with alterations in gliosis and synaptic protein levels in the hippocampus of female mice.

In general, human data support the concept that APOE4 and female sex interact to exacerbate $\mathrm{AD}$ risk and pathology. For example, APOE4 confers a greater lifetime risk of $\mathrm{AD}$ and accelerated degeneration rates in females compared to males (Payami et al., 1994; Farrer et al., 1997; Riedel et al., 2016). The changes that result in this increased risk are typically thought to occur post-menopause, however, in vivo studies demonstrate that APOE4-female sex interactions occur independent of changes in sex hormones (Grootendorst et al., 2005; Bour et al., 2008; Leung et al., 2012; Siegel et al., 2012; Segev et al., 2013; Tai et al., 2017). Although there are multiple caveats, in our study design we attempted to select ages that matched AD-relevant pathology by treating male mice at a later timepoint (8-12 months of age) than female mice (6-10 months of age). Thus, one potential explanation for our data is that candesartan targets dysfunctional pathways that contribute to altered neuron function to a greater extent in females than in males that express APOE4; one such pathway could be neuroinflammation. Although we did not perform analysis of inflammation on tissue from male E4FAD - and E4FAD + mice (we encountered a technical issue that resulted in sample spoiling), published data support this concept as in general, females experience earlier and more aggressive neuroinflammation with age than males (Hanamsagar and Bilbo, 2016; Spychala et al., 2017; Doran et al., 2019), and female E4FAD + mice have higher hippocampal and cortical astrogliosis compared to E3FAD + mice (Balu et al., 2019; Stephen et al., 2019). Therefore, female mice that express APOE4 may be more susceptible to neuroinflammation-associated memory dysfunction with age. Another potential pathway underlying the differences in treatment effects by sex, is that angiotensin II levels and/or AT1 receptor activation are higher in APOE4 females than males. While sexual dimorphisms in angiotensin II metabolism, angiotensin receptor expression levels, and angiotensin receptor activation have been reported in the periphery (Thomas et al., 2016, 2017; Zaldua et al., 2020), there is limited data available regarding the effects of biological sex on brain angiotensin peptide and receptor levels. Although in the present study, treatment did not alter angiotensin peptide or receptor levels, a focus of our ongoing studies is identification of the extent that the angiotensin II/AT1 receptor axis is differentially influenced by age, sex, $A \beta$, and $A P O E$ genotype.

Recent evidence supports the idea that regardless of high human $\mathrm{A} \beta$ levels, APOE4 is sufficient to cause behavioral and neuronal dysfunction in female mice (Sullivan, 2008; Leete et al., 2018). In fact, our results suggest that ARBs have the potential to mitigate APOE4-associted deficits in female mice even in the absence of $\mathrm{A} \beta$ overproduction and that candesartan may be acting through $\mathrm{A} \beta$-independent pathways in the brain. That we saw identical treatment benefits in both E4FAD - and E4FAD+ female mice and that we did not observe any lowering of $A \beta$ levels after treatment in E4FAD + mice, also brings up an important point regarding the overall effect of $A R B s$ on $A \beta$ pathology, of which there are contrasting data. Indeed, while some studies in FAD mice have reported profound reductions in $\mathrm{A} \beta$ levels with ARB treatment (Wang et al., 2007; Mogi et al., 2008; 
Danielyan et al., 2010; Torika et al., 2016, 2017, 2018), others have shown no effects (Mogi et al., 2008; Ferrington et al., 2011, 2012; Ongali et al., 2014; Royea et al., 2017; Trigiani et al., 2018; Royea et al., 2020). These discrepancies may be related to a secondary property of certain ARBs: activation of Peroxisome Proliferator- Activated Receptor $\gamma(\operatorname{PPAR} \gamma)$. PPAR $\gamma$ is a nuclear hormone receptor that plays an important role in fatty acid storage, glucose metabolism, and inflammation. Importantly, nuclear receptor agonists (Tai et al., 2014a; Koster et al., 2017; Moutinho et al., 2019) including for PPAR $\gamma$ (Camacho et al., 2004), lower $A \beta$ levels in FAD mice and increase $A \beta$ clearance in cellular models in vitro. Therefore, since different ARBs have different PPAR $\gamma$-activating properties, this could explain why some studies found robust $A \beta$ effects following ARB treatment while others did not. Ultimately, combined with the results of previous studies, our data suggest that ARB treatment in FAD mice modulates learning and memory-type behavior, synaptic function, and neuroinflammation, independent of alterations in $A \beta$ levels, and in the absence of $A \beta$ overproduction altogether (E4FAD- mice). However, we cannot eliminate the prospect that candesartan treatment in E4FAD+ mice partially restored behavioral and synaptic deficits induced by $\mathrm{A} \beta$.

APOE4 is linked to alterations in neuronal function throughout the brain; however, dysfunctions in the hippocampus are particularly important in the context of learning and memory-type behavior. Indeed, our data suggest that the effects of candesartan in female E4FAD - and E4FAD+ mice were localized primarily to the hippocampus as this is where reductions in glial cell number/activation and improvements in synaptic protein levels were observed. The cerebral cortex is another region of the brain that is closely linked to memory and cognition; however, in the current study, candesartan did not appear to modulate synaptic protein levels or gliosis in the cortex of female E4FAD+ mice. One potential explanation for the lack of effects in the cortex, is that changes were concentrated only in certain cortical subregions, for example the prefrontal cortex, or in certain cortical layers. Alternatively, concentrations of the AT1 receptor may differ by brain region in E4FAD mice, with higher concentrations present on cells in the hippocampus as compared to the cortex. While it is well established that the distribution of the AT1 receptor is heterogeneous in the brains of wild type mice (Allen et al., 1998) and rats (Lenkei et al., 1997), no such localization studies have been conducted in FAD rodents. It is therefore possible that the relative distribution of the AT1 receptor by brain region is differentially affected by biological sex, $\mathrm{A} \beta$, and/or $A P O E$ genotype. There are several additional explanations such as brain region differences in candesartan pharmacokinetics, variations in the influence of inflammation on synaptic function by brain region, and changes with candesartan treatment for neuroinflammatory and synaptic readouts differed from those that we measured in this study.

\section{Limitations}

Overall, due to the nature of our study design there are limitations on the type of mechanistic and therapeutic insights that we can provide surrounding the applicability of ARBs for the treatment of $\mathrm{AD}$. One issue is that we did not identify the precise cellular functional mechanism(s) that underlie the beneficial effects of candesartan in mice that express human APOE4. Although suggested by our correlative data, we are unable to draw the strict conclusion that candesartan improves memory and synaptic function by modulating neuroinflammation in E4FAD female mice. In addition, our study has raised an additional set of key questions including: Why was ARB treatment beneficial in female and not male mice that express human APOE4? What is the optimal treatment age, dose, and duration for ARB treatment of E4FAD mice? Would ARBs be beneficial in mice that express APOE3? Is candesartan the optimal therapeutic candidate? What is the endogenous function of brain AT1 receptor signaling in physiological conditions and during neurodegeneration? To help address these issues our current research is focused on understanding how $A P O E$ genotype, $\mathrm{A} \beta$ levels, age, and sex interact to modulate the angiotensin II/AT1 receptor axis in different brain regions of EFAD mice in relation to neuroinflammation and altered behavioral function. Such an understanding will form the basis for further mechanistic (e.g., identify the source of angiotensin II in the brain along with the functional effects of cell-type specific AT1 receptor knockdown) and preclinical therapeutic studies (e.g., vary age of treatment onset, duration of treatment, and route of administration). Finally, a limitation of the current study is that we restricted analysis to candesartan. Therefore, from a therapeutic standpoint, detailed preclinical ARB treatment studies are required with in-depth pharmacokinetic analyses in order to determine whether any of the currently available $\mathrm{ARBs}$ are optimal candidates for the treatment of $\mathrm{AD}$, or if there may be more therapeutic potential in developing a new ARB that is optimized for PPAR $\gamma$ activating properties and brain penetrance. Addressing these questions are fundamental next steps for translating findings from ARB treatment studies in $\mathrm{AD}$-relevant rodent models into therapeutic strategies for human $\mathrm{AD}$ patients.

\section{SUMMARY}

The goal of this study was to evaluate the activity of longterm ARB treatment at modulating AD-relevant pathology in mice that express human APOE4. Our data demonstrate that ARB treatment is beneficial for memory-relevant behavior, hippocampal synaptic protein levels, and neuroinflammation in female mice that express APOE4 both in the presence $(\mathrm{E} 4 \mathrm{FAD}+)$ and absence (E4FAD-) of high $\mathrm{A} \beta$ levels. Thus, development of therapies targeting the angiotensin II/AT1 receptor axis could provide options for neuroinflammation in female APOE4 carriers.

\section{DATA AVAILABILITY STATEMENT}

The raw data supporting the conclusions of this article will be made available by the authors, without undue reservation. 


\section{ETHICS STATEMENT}

The animal study was reviewed and approved by UIC Institutional Animal Care and Use Committee.

\section{AUTHOR CONTRIBUTIONS}

LMT, SBS, and GRJT conceived and designed the experiments, performed the experiments, analyzed and interpreted the data, and wrote the manuscript. SZ, $\mathrm{AD}, \mathrm{KK}, \mathrm{KD}$, and FMM performed the experiments. All authors contributed to the article and approved the submitted version.

\section{REFERENCES}

Allen, A. M., Moeller, I., Jenkins, T. A., Zhuo, J., Aldred, G. P., Chai, S. Y., et al. (1998). Angiotensin receptors in the nervous system. Brain Res. Bull. 47, 17-28. doi: 10.1016/s0361-9230(98)00039-2

Balducci, C., Santamaria, G., La Vitola, P., Brandi, E., Grandi, F., Viscomi, A. R., et al. (2018). Doxycycline counteracts neuroinflammation restoring memory in Alzheimer's disease mouse models. Neurobiol. Aging 70, 128-139. doi: 10.1016/ j.neurobiolaging.2018.06.002

Balu, D., Karstens, A. J., Loukenas, E., Maldonado Weng, J., York, J. M., ValenciaOlvera, A. C., et al. (2019). The role of APOE in transgenic mouse models of AD. Neurosci. Lett. 707:134285. doi: 10.1016/j.neulet.2019.134285

Bandaru, V. V., Troncoso, J., Wheeler, D., Pletnikova, O., Wang, J., Conant, K., et al. (2009). ApoE4 disrupts sterol and sphingolipid metabolism in Alzheimer's but not normal brain. Neurobiol. Aging 30, 591-599. doi: 10.1016/j. neurobiolaging.2007.07.024

Benicky, J., Sanchez-Lemus, E., Honda, M., Pang, T., Orecna, M., Wang, J., et al. (2011). Angiotensin II AT1 receptor blockade ameliorates brain inflammation. Neuropsychopharmacology 36, 857-870. doi: 10.1038/npp.20 10.225

Benicky, J., Sanchez-Lemus, E., Pavel, J., and Saavedra, J. M. (2009). Antiinflammatory effects of angiotensin receptor blockers in the brain and the periphery. Cell. Mol. Neurobiol. 29, 781-792. doi: 10.1007/s10571-009-9368-4

Bour, A., Grootendorst, J., Vogel, E., Kelche, C., Dodart, J. C., Bales, K., et al. (2008). Middle-aged human apoE4 targeted-replacement mice show retention deficits on a wide range of spatial memory tasks. Behav. Brain Res. 193, 174-182. doi: 10.1016/j.bbr.2008.05.008

$\mathrm{Bu}, \mathrm{G}$. (2009). Apolipoprotein E and its receptors in Alzheimer's disease: pathways, pathogenesis and therapy. Nat. Rev. Neurosci. 10, 333-344. doi: 10.1038/ nrn2620

Camacho, I. E., Serneels, L., Spittaels, K., Merchiers, P., Dominguez, D., and De Strooper, B. (2004). Peroxisome-proliferator-activated receptor gamma induces a clearance mechanism for the amyloid-beta peptide. J. Neurosci. 24, 1090810917. doi: 10.1523/JNEUROSCI.3987-04.2004

Carter, D. B. (2005). The interaction of amyloid-beta with ApoE. Subcell. Biochem. 38, 255-272. doi: 10.1007/0-387-23226-5_13

Cui, C., Xu, P., Li, G., Qiao, Y., Han, W., Geng, C., et al. (2019). Vitamin D receptor activation regulates microglia polarization and oxidative stress in spontaneously hypertensive rats and angiotensin II-exposed microglial cells: role of renin-angiotensin system. Redox Biol. 26:101295. doi: 10.1016/j.redox. 2019.101295

Danielyan, L., Klein, R., Hanson, L. R., Buadze, M., Schwab, M., Gleiter, C. H., et al. (2010). Protective effects of intranasal losartan in the APP/PS1 transgenic mouse model of Alzheimer disease. Rejuvenation Res. 13, 195-201. doi: 10.1089/ rej.2009.0944

Davies, N. M., Kehoe, P. G., Ben-Shlomo, Y., and Martin, R. M. (2011). Associations of anti-hypertensive treatments with Alzheimer's disease, vascular dementia, and other dementias. J. Alzheimers Dis. 26, 699-708. doi: 10.3233/ JAD-2011-110347

\section{FUNDING}

LMT was supported by National Institutes of Health Grants R01AG061114, R01AG061114-01S1, R21AG061715, and R21AG053876 and University of Illinois at Chicago institutional start-up funds. GRJT was supported by $\mathrm{NIH}$ UL1TR002003 (UICentre).

\section{SUPPLEMENTARY MATERIAL}

The Supplementary Material for this article can be found online at: https://www.frontiersin.org/articles/10.3389/fnins. 2021.628403/full\#supplementary-material

Doran, S. J., Ritzel, R. M., Glaser, E. P., Henry, R. J., Faden, A. I., and Loane, D. J. (2019). Sex differences in acute neuroinflammation after experimental traumatic brain injury are mediated by infiltrating myeloid cells. J. Neurotrauma 36, 1040-1053. doi: 10.1089/neu.2018.6019

Elsaafien, K., de Kloet, A. D., Krause, E. G., and Sumners, C. (2020). Brain angiotensin type-1 and type-2 receptors in physiological and hypertensive conditions: focus on neuroinflammation. Curr. Hypertens. Rep. 22, 48. doi: 10.1007/s11906-020-01062-0

Farrer, L. A., Cupples, L. A., Haines, J. L., Hyman, B., Kukull, W. A., Mayeux, R., et al. (1997). Effects of age, sex, and ethnicity on the association between apolipoprotein E genotype and Alzheimer disease. A meta-analysis. APOE and Alzheimer disease meta analysis consortium. JAMA 278, 1349-1356. doi: 10. 1001/jama.278.16.1349

Fernandez, C. G., Hamby, M. E., McReynolds, M. L., and Ray, W. J. (2019). The role of APOE4 in Disrupting the homeostatic functions of astrocytes and microglia in aging and Alzheimer's disease. Front. Aging Neurosci. 11:14. doi: 10.3389/fnagi.2019.00014

Ferrington, L., Miners, J. S., Palmer, L. E., Bond, S. M., Povey, J. E., Kelly, P. A., et al. (2011). Angiotensin II-inhibiting drugs have no effect on intraneuronal Abeta or oligomeric Abeta levels in a triple transgenic mouse model of Alzheimer's disease. Am. J. Transl. Res. 3, 197-208.

Ferrington, L., Palmer, L. E., Love, S., Horsburgh, K. J., Kelly, P. A., and Kehoe, P. G. (2012). Angiotensin II-inhibition: effect on Alzheimer's pathology in the aged triple transgenic mouse. Am. J. Transl. Res. 4, 151-164.

Fleegal-DeMotta, M. A., Doghu, S., and Banks, W. A. (2009). Angiotensin II modulates $\mathrm{BBB}$ permeability via activation of the $\mathrm{AT}(1)$ receptor in brain endothelial cells. J. Cereb. Blood Flow Metab. 29, 640-647. doi: 10.1038/jcbfm. 2008.158

Fliser, D., Buchholz, K., Haller, H., and EUropean Trial on Olmesartan and Pravastatin in Inflammation and Atherosclerosis (Eutopia) Investigators (2004). Antiinflammatory effects of angiotensin II subtype 1 receptor blockade in hypertensive patients with microinflammation. Circulation 110, 1103-1107. doi: 10.1161/01.CIR.0000140265.21608.8E

Fogarty, D. J., and Matute, C. (2001). Angiotensin receptor-like immunoreactivity in adult brain white matter astrocytes and oligodendrocytes. Glia 35, 131-146. doi: $10.1002 /$ glia.1078

Fuchtbauer, L., Groth-Rasmussen, M., Holm, T. H., Lobner, M., Toft-Hansen, H., Khorooshi, R., et al. (2011). Angiotensin II Type 1 receptor (AT1) signaling in astrocytes regulates synaptic degeneration-induced leukocyte entry to the central nervous system. Brain Behav. Immun. 25, 897-904. doi: 10.1016/j.bbi. 2010.09.015

Gale, S. C., Gao, L., Mikacenic, C., Coyle, S. M., Rafaels, N., Murray Dudenkov, T., et al. (2014). APOepsilon4 is associated with enhanced in vivo innate immune responses in human subjects. J. Allergy Clin. Immunol. 134, 127-134. doi: 10.1016/j.jaci.2014.01.032

Gohlke, P., Kox, T., Jurgensen, T., von Kugelgen, S., Rascher, W., Unger, T., et al. (2002). Peripherally applied candesartan inhibits central responses to angiotensin II in conscious rats. Naunyn Schmiedebergs Arch. Pharmacol. 365, 477-483. doi: 10.1007/s00210-002-0545-y 
Gregg, R. E., Zech, L. A., Schaefer, E. J., Stark, D., Wilson, D., and Brewer, H. B. Jr. (1986). Abnormal in vivo metabolism of apolipoprotein E4 in humans. J. Clin. Invest. 78, 815-821. doi: 10.1172/JCI112645

Grootendorst, J., Bour, A., Vogel, E., Kelche, C., Sullivan, P. M., Dodart, J. C., et al. (2005). Human apoE targeted replacement mouse lines: h-apoE4 and h-apoE3 mice differ on spatial memory performance and avoidance behavior. Behav. Brain Res. 159, 1-14. doi: 10.1016/j.bbr.2004.09.019

Guo, L., LaDu, M. J., and Van Eldik, L. J. (2004). A dual role for apolipoprotein e in neuroinflammation: anti- and pro-inflammatory activity. J. Mol. Neurosci. 23, 205-212. doi: 10.1385/jmn:23:3:205

Habib, N., McCabe, C., Medina, S., Varshavsky, M., Kitsberg, D., Dvir-Szternfeld, R., et al. (2020). Disease-associated astrocytes in Alzheimer's disease and aging. Nat. Neurosci. 23, 701-706. doi: 10.1038/s41593-020-0624-8

Hajjar, I., Brown, L., Mack, W. J., and Chui, H. (2012). Impact of angiotensin receptor blockers on Alzheimer disease neuropathology in a large brain autopsy series. Arch. Neurol. 69, 1632-1638. doi: 10.1001/archneurol.2012. 1010

Hanamsagar, R., and Bilbo, S. D. (2016). Sex differences in neurodevelopmental and neurodegenerative disorders: focus on microglial function and neuroinflammation during development. J. Steroid Biochem. Mol. Biol. 160, 127-133. doi: 10.1016/j.jsbmb.2015.09.039

Hein, A. M., and O'Banion, M. K. (2009). Neuroinflammation and memory: the role of prostaglandins. Mol. Neurobiol. 40, 15-32. doi: 10.1007/s12035-0098066-z

Ho, J. K., Nation, D. A., and Alzheimer's Disease Neuroimaging, Initiative (2017). Memory is preserved in older adults taking AT1 receptor blockers. Alzheimers Res. Ther. 9:33. doi: 10.1186/s13195-017-0255-9

Hoffman, L. B., Schmeidler, J., Lesser, G. T., Beeri, M. S., Purohit, D. P., Grossman, H. T., et al. (2009). Less Alzheimer disease neuropathology in medicated hypertensive than nonhypertensive persons. Neurology 72, 1720-1726. doi: 10. 1212/01.wnl.0000345881.82856.d5

Holtzman, D. M., Herz, J., and Bu, G. (2012). Apolipoprotein E and apolipoprotein E receptors: normal biology and roles in Alzheimer disease. Cold Spring Harb. Perspect. Med. 2:a006312. doi: 10.1101/cshperspect.a006312

Hsu, C. Y., Huang, C. C., Chan, W. L., Huang, P. H., Chiang, C. H., Chen, T. J., et al. (2013). Angiotensin-receptor blockers and risk of Alzheimer's disease in hypertension population-a nationwide cohort study. Circ. J. 77, 405-410. doi: 10.1253/circj.cj-12-0658

Huang, Y., and Mahley, R. W. (2014). Apolipoprotein E: structure and function in lipid metabolism, neurobiology, and Alzheimer's diseases. Neurobiol. Dis. 72 (Pt A), 3-12. doi: 10.1016/j.nbd.2014.08.025

Keren-Shaul, H., Spinrad, A., Weiner, A., Matcovitch-Natan, O., Dvir-Szternfeld, R., Ulland, T. K., et al. (2017). A unique microglia type associated with restricting development of Alzheimer's disease. Cell 169, 1276-1290.e1217. doi: 10.1016/j.cell.2017.05.018

Kim, J., Basak, J. M., and Holtzman, D. M. (2009). The role of apolipoprotein E in Alzheimer's disease. Neuron 63, 287-303. doi: 10.1016/j.neuron.2009. 06.026

Koster, K. P., Smith, C., Valencia-Olvera, A. C., Thatcher, G. R., Tai, L. M., and LaDu, M. J. (2017). Rexinoids as therapeutics for Alzheimer's disease: role of APOE. Curr. Top. Med. Chem. 17, 708-720. doi: 10.2174/ 1568026616666160617090227

Kume, K., Hanyu, H., Sakurai, H., Takada, Y., Onuma, T., and Iwamoto, T. (2012). Effects of telmisartan on cognition and regional cerebral blood flow in hypertensive patients with Alzheimer's disease. Geriatr. Gerontol. Int. 12, 207-214. doi: 10.1111/j.1447-0594.2011.00746.x

Kurihara, T., Ozawa, Y., Nagai, N., Shinoda, K., Noda, K., Imamura, Y., et al. (2008). Angiotensin II type 1 receptor signaling contributes to synaptophysin degradation and neuronal dysfunction in the diabetic retina. Diabetes 57, 2191-2198. doi: 10.2337/db07-1281

Kurinami, H., Shimamura, M., Sato, N., Nakagami, H., and Morishita, R. (2013). Do angiotensin receptor blockers protect against Alzheimer's disease? Drugs Aging 30, 367-372. doi: 10.1007/s40266-013-0071-2

Kurtz, T. W., and Klein, U. (2009). Next generation multifunctional angiotensin receptor blockers. Hypertens. Res. 32, 826-834. doi: 10.1038/hr.2009.135

LaDu, M. J., Falduto, M. T., Manelli, A. M., Reardon, C. A., Getz, G. S., and Frail, D. E. (1994). Isoform-specific binding of apolipoprotein E to beta-amyloid. J. Biol. Chem. 269, 23403-23406. doi: 10.1016/s0021-9258(17)31529-6
Lanz, T. V., Ding, Z., Ho, P. P., Luo, J., Agrawal, A. N., Srinagesh, H., et al. (2010). Angiotensin II sustains brain inflammation in mice via TGF-beta. J. Clin. Invest. 120, 2782-2794. doi: 10.1172/JCI41709

Launer, L. J., Ross, G. W., Petrovitch, H., Masaki, K., Foley, D., White, L. R., et al. (2000). Midlife blood pressure and dementia: the Honolulu-Asia aging study. Neurobiol. Aging 21, 49-55. doi: 10.1016/s0197-4580(00)00096-8

Leete, J., Gurley, S., and Layton, A. (2018). Modeling sex differences in the renin angiotensin system and the efficacy of antihypertensive therapies. Comput. Chem. Eng. 112, 253-264. doi: 10.1016/j.compchemeng.2018.02.009

Lenkei, Z., Palkovits, M., Corvol, P., and Llorens-Cortes, C. (1997). Expression of angiotensin type-1 (AT1) and type-2 (AT2) receptor mRNAs in the adult rat brain: a functional neuroanatomical review. Front. Neuroendocrinol. 18:383439. doi: 10.1006/frne.1997.0155

Leung, L., Andrews-Zwilling, Y., Yoon, S. Y., Jain, S., Ring, K., Dai, J., et al. (2012). Apolipoprotein E4 causes age- and sex-dependent impairments of hilar GABAergic interneurons and learning and memory deficits in mice. PLoS One 7:e53569. doi: 10.1371/journal.pone.0053569

Lewandowski, C. T., Maldonado Weng, J., and LaDu, M. J. (2020). Alzheimer's disease pathology in APOE transgenic mouse models: the who, what, when, where, why, and how. Neurobiol. Dis. 139:104811. doi: 10.1016/j.nbd.2020. 104811

Li, D. P., Chen, S. R., and Pan, H. L. (2003). Angiotensin II stimulates spinally projecting paraventricular neurons through presynaptic disinhibition. J. Neurosci. 23, 5041-5049. doi: 10.1523/jneurosci.23-12-05041.2003

Li, D. P., and Pan, H. L. (2005). Angiotensin II attenuates synaptic GABA release and excites paraventricular-rostral ventrolateral medulla output neurons. J. Pharmacol. Exp. Ther. 313, 1035-1045. doi: 10.1124/jpet.104.082495

Li, N. C., Lee, A., Whitmer, R. A., Kivipelto, M., Lawler, E., Kazis, L. E., et al. (2010). Use of angiotensin receptor blockers and risk of dementia in a predominantly male population: prospective cohort analysis. BMJ 340:b5465. doi: 10.1136/bmj. b5465

Liu, D. S., Pan, X. D., Zhang, J., Shen, H., Collins, N. C., Cole, A. M., et al. (2015). APOE4 enhances age-dependent decline in cognitive function by downregulating an NMDA receptor pathway in EFAD-Tg mice. Mol. Neurodegener. 10:7. doi: 10.1186/s13024-015-0002-2

Liu, G., Hosomi, N., Hitomi, H., Pelisch, N., Fu, H., Masugata, H., et al. (2011). Angiotensin II induces human astrocyte senescence through reactive oxygen species production. Hypertens. Res. 34, 479-483. doi: 10.1038/hr.2010.269

MacGregor, D. P., Murone, C., Song, K., Allen, A. M., Paxinos, G., and Mendelsohn, F. A. (1995). Angiotensin II receptor subtypes in the human central nervous system. Brain Res. 675, 231-240. doi: 10.1016/0006-8993(95) 00076-3

Maldonado Weng, J., Parikh, I., Naqib, A., York, J., Green, S. J., Estus, S., et al. (2019). Synergistic effects of APOE and sex on the gut microbiome of young EFAD transgenic mice. Mol. Neurodegener. 14:47. doi: 10.1186/s13024-0190352-2

Marchesi, C., Paradis, P., and Schiffrin, E. L. (2008). Role of the renin-angiotensin system in vascular inflammation. Trends Pharmacol. Sci. 29, 367-374. doi: 10.1016/j.tips.2008.05.003

Marottoli, F. M., Katsumata, Y., Koster, K. P., Thomas, R., Fardo, D. W., and Tai, L. M. (2017). Peripheral inflammation, apolipoprotein E4, and amyloidbeta interact to induce cognitive and cerebrovascular dysfunction. ASN Neuro 9:1759091417719201. doi: 10.1177/1759091417719201

Marottoli, F. M., Priego, M., Flores-Barrera, E., Pisharody, R., Zaldua, S., Fan, K. D., et al. (2019). EGF treatment improves motor behavior and cortical GABAergic function in the R6/2 mouse model of huntington's disease. Mol. Neurobiol. 56, 7708-7718. doi: 10.1007/s12035-019-1634-y

McKinley, M. J., Albiston, A. L., Allen, A. M., Mathai, M. L., May, C. N., McAllen, R. M., et al. (2003). The brain renin-angiotensin system: location and physiological roles. Int. J. Biochem. Cell Biol. 35, 901-918. doi: 10.1016/s13572725(02)00306-0

Michel, M. C., Foster, C., Brunner, H. R., and Liu, L. (2013). A systematic comparison of the properties of clinically used angiotensin II type 1 receptor antagonists. Pharmacol. Rev. 65, 809-848. doi: 10.1124/pr.112. 007278

Mogi, M., Li, J. M., Tsukuda, K., Iwanami, J., Min, L. J., Sakata, A., et al. (2008). Telmisartan prevented cognitive decline partly due to PPAR-gamma activation. Biochem. Biophys. Res. Commun. 375, 446-449. doi: 10.1016/j.bbrc.2008.08.032 
Moutinho, M., Codocedo, J. F., Puntambekar, S. S., and Landreth, G. E. (2019). Nuclear receptors as therapeutic targets for neurodegenerative diseases: lost in translation. Annu. Rev. Pharmacol. Toxicol. 59, 237-261. doi: 10.1146/annurevpharmtox-010818-021807

Nishimura, Y., Ito, T., Hoe, K., and Saavedra, J. M. (2000). Chronic peripheral administration of the angiotensin II AT(1) receptor antagonist candesartan blocks brain AT(1) receptors. Brain Res. 871, 29-38. doi: 10.1016/s00068993(00)02377-5

Ongali, B., Nicolakakis, N., Tong, X. K., Aboulkassim, T., Imboden, H., and Hamel, E. (2016). Enalapril alone or co-administered with losartan rescues cerebrovascular dysfunction, but not mnemonic deficits or amyloidosis in a mouse model of Alzheimer's disease. J. Alzheimers Dis. 51, 1183-1195. doi: 10.3233/JAD- 150868

Ongali, B., Nicolakakis, N., Tong, X. K., Aboulkassim, T., Papadopoulos, P., RosaNeto, P., et al. (2014). Angiotensin II type 1 receptor blocker losartan prevents and rescues cerebrovascular, neuropathological and cognitive deficits in an Alzheimer's disease model. Neurobiol. Dis. 68, 126-136. doi: 10.1016/j.nbd. 2014.04.018

Pang, T., Benicky, J., Wang, J., Orecna, M., Sanchez-Lemus, E., and Saavedra, J. M. (2012). Telmisartan ameliorates lipopolysaccharide-induced innate immune response through peroxisome proliferator-activated receptor-gamma activation in human monocytes. J. Hypertens. 30, 87-96. doi: 10.1097/HJH. 0b013e32834dde5f

Parikh, I. J., Estus, J. L., Zajac, D. J., Malik, M., Maldonado Weng, J., Tai, L. M., et al. (2020). Murine gut microbiome association with APOE alleles. Front. Immunol. 11:200. doi: 10.3389/fimmu.2020.00200

Payami, H., Montee, K. R., Kaye, J. A., Bird, T. D., Yu, C. E., Wijsman, E. M., et al. (1994). Alzheimer's disease, apolipoprotein E4, and gender. JAMA 271, 1316-1317. doi: 10.1001/jama.271.17.1316

Phipps, J. A., Vessey, K. A., Brandli, A., Nag, N., Tran, M. X., Jobling, A. I., et al. (2018). The role of angiotensin II/AT1 receptor signaling in regulating retinal microglial activation. Invest. Ophthalmol. Vis. Sci. 59, 487-498. doi: 10.1167/ iovs.17-22416

Qiu, T., Liu, Q., Chen, Y. X., Zhao, Y. F., and Li, Y. M. (2015). Abeta42 and Abeta40: similarities and differences. J. Pept. Sci. 21, 522-529. doi: 10.1002/psc.2789

Riedel, B. C., Thompson, P. M., and Brinton, R. D. (2016). Age, APOE and sex: triad of risk of Alzheimer's disease. J. Steroid Biochem. Mol. Biol. 160, 134-147. doi: 10.1016/j.jsbmb.2016.03.012

Royea, J., Lacalle-Aurioles, M., Trigiani, L. J., Fermigier, A., and Hamel, E. (2020). AT2R's (angiotensin II Type 2 Receptor's) role in cognitive and cerebrovascular deficits in a mouse model of Alzheimer disease. Hypertension 75, 1464-1474. doi: 10.1161/HYPERTENSIONAHA.119.14431

Royea, J., Zhang, L., Tong, X. K., and Hamel, E. (2017). Angiotensin IV receptors mediate the cognitive and cerebrovascular benefits of losartan in a mouse model of Alzheimer's disease. J. Neurosci. 37, 5562-5573. doi: 10.1523/JNEUROSCI. 0329- 17.2017

Saavedra, J. M. (2012a). Angiotensin II AT(1) receptor blockers ameliorate inflammatory stress: a beneficial effect for the treatment of brain disorders. Cell. Mol. Neurobiol. 32, 667-681. doi: 10.1007/s10571-0119754-6

Saavedra, J. M. (2012b). Angiotensin II AT(1) receptor blockers as treatments for inflammatory brain disorders. Clin. Sci. (Lond.) 123, 567-590. doi: 10.1042/ CS20120078

Saavedra, J. M. (2016). Evidence to consider angiotensin II receptor blockers for the treatment of early Alzheimer's disease. Cell. Mol. Neurobiol. 36, 259-279. doi: 10.1007/s10571-015-0327-y

Sakai, K., Agassandian, K., Morimoto, S., Sinnayah, P., Cassell, M. D., Davisson, R. L., et al. (2007). Local production of angiotensin II in the subfornical organ causes elevated drinking. J. Clin. Invest. 117, 1088-1095. doi: 10.1172/JCI 31242

Sandgren, J. A., Linggonegoro, D. W., Zhang, S. Y., Sapouckey, S. A., Claflin, K. E., Pearson, N. A., et al. (2018). Angiotensin AT1A receptors expressed in vasopressin-producing cells of the supraoptic nucleus contribute to osmotic control of vasopressin. Am. J. Physiol. Regul. Integr. Comp. Physiol. 314, R770R780. doi: 10.1152/ajpregu.00435.2017

Schlachetzki, J. C., and Hull, M. (2009). Microglial activation in Alzheimer's disease. Curr. Alzheimer Res. 6, 554-563. doi: 10.2174/15672050979014 7179
Segev, Y., Michaelson, D. M., and Rosenblum, K. (2013). ApoE epsilon4 is associated with eIF2alpha phosphorylation and impaired learning in young mice. Neurobiol. Aging 34, 863-872. doi: 10.1016/j.neurobiolaging.2012.06.020

Siegel, J. A., Haley, G. E., and Raber, J. (2012). Apolipoprotein E isoform-dependent effects on anxiety and cognition in female TR mice. Neurobiol. Aging 33, 345-358. doi: 10.1016/j.neurobiolaging.2010.03.002

Simpson, J. E., Ince, P. G., Lace, G., Forster, G., Shaw, P. J., Matthews, F., et al. (2010). Astrocyte phenotype in relation to Alzheimer-type pathology in the ageing brain. Neurobiol. Aging 31, 578-590. doi: 10.1016/j.neurobiolaging.2008. 05.015

Spanos, F., and Liddelow, S. A. (2020). An overview of astrocyte responses in genetically induced Alzheimer's disease mouse models. Cells 9:2415. doi: 10. 3390/cells9112415

Speth, R. C., Wamsley, J. K., Gehlert, D. R., Chernicky, C. L., Barnes, K. L., and Ferrario, C. M. (1985). Angiotensin II receptor localization in the canine CNS. Brain Res. 326, 137-143. doi: 10.1016/0006-8993(85)91392-7

Spychala, M. S., Honarpisheh, P., and McCullough, L. D. (2017). Sex differences in neuroinflammation and neuroprotection in ischemic stroke. J. Neurosci. Res. 95, 462-471. doi: 10.1002/jnr.23962

Stephen, T. L., Cacciottolo, M., Balu, D., Morgan, T. E., LaDu, M. J., Finch, C. E., et al. (2019). APOE genotype and sex affect microglial interactions with plaques in Alzheimer's disease mice. Acta Neuropathol. Commun. 7:82. doi: 10.1186/ s40478-019-0729-z

Sullivan, J. C. (2008). Sex and the renin-angiotensin system: inequality between the sexes in response to RAS stimulation and inhibition. Am. J. Physiol. Regul. Integr. Comp. Physiol. 294, R1220-R1226. doi: 10.1152/ajpregu.00864.2007

Sumners, C., Zhu, M., Gelband, C. H., and Posner, P. (1996). Angiotensin II type 1 receptor modulation of neuronal $\mathrm{K}+$ and $\mathrm{Ca} 2+$ currents: intracellular mechanisms. Am. J. Physiol. 271(1 Pt 1), C154-C163. doi: 10.1152/ajpcell.1996. 271.1.C154

Sun, H., Wu, H., Yu, X., Zhang, G., Zhang, R., Zhan, S., et al. (2015). Angiotensin II and its receptor in activated microglia enhanced neuronal loss and cognitive impairment following pilocarpine-induced status epilepticus. Mol. Cell. Neurosci. 65, 58-67. doi: 10.1016/j.mcn.2015.02.014

Tai, L. M., Balu, D., Avila-Munoz, E., Abdullah, L., Thomas, R., Collins, N., et al. (2017). EFAD transgenic mice as a human APOE relevant preclinical model of Alzheimer's disease. J. Lipid Res. 58, 1733-1755. doi: 10.1194/jlr.R076315

Tai, L. M., Bilousova, T., Jungbauer, L., Roeske, S. K., Youmans, K. L., Yu, C., et al. (2013). Levels of soluble apolipoprotein E/amyloid-beta (Abeta) complex are reduced and oligomeric Abeta increased with APOE4 and Alzheimer disease in a transgenic mouse model and human samples. J. Biol. Chem. 288, 5914-5926. doi: 10.1074/jbc.M112.442103

Tai, L. M., Ghura, S., Koster, K. P., Liakaite, V., Maienschein-Cline, M., Kanabar, P., et al. (2015). APOE-modulated Abeta-induced neuroinflammation in Alzheimer's disease: current landscape, novel data, and future perspective. J. Neurochem. 133, 465-488. doi: 10.1111/jnc.13072

Tai, L. M., Koster, K. P., Luo, J., Lee, S. H., Wang, Y. T., Collins, N. C., et al. (2014a). Amyloid-beta pathology and APOE genotype modulate retinoid X receptor agonist activity in vivo. J. Biol. Chem. 289, 30538-30555. doi: 10.1074/jbc.M114. 600833

Tai, L. M., Mehra, S., Shete, V., Estus, S., Rebeck, G. W., Bu, G., et al. (2014b). Soluble apoE/Abeta complex: mechanism and therapeutic target for APOE4induced AD risk. Mol. Neurodegener. 9:2. doi: 10.1186/1750-1326-9-2

Takeda, S., Sato, N., Takeuchi, D., Kurinami, H., Shinohara, M., Niisato, K., et al. (2009). Angiotensin receptor blocker prevented beta-amyloid-induced cognitive impairment associated with recovery of neurovascular coupling. Hypertension 54, 1345-1352. doi: 10.1161/HYPERTENSIONAHA.109.138586

Thomas, R., Morris, A. W. J., and Tai, L. M. (2017). Epidermal growth factor prevents APOE4-induced cognitive and cerebrovascular deficits in female mice. Heliyon 3:e00319. doi: 10.1016/j.heliyon.2017.e00319

Thomas, R., Zuchowska, P., Morris, A. W., Marottoli, F. M., Sunny, S., Deaton, R., et al. (2016). Epidermal growth factor prevents APOE4 and amyloidbeta-induced cognitive and cerebrovascular deficits in female mice. Acta Neuropathol. Commun. 4:111. doi: 10.1186/s40478-016-0387-3

Tonelli, L., Johren, O., Hoe, K. L., Hauser, W., and Saavedra, J. M. (2000). Gerbil angiotensin II AT1 receptors are highly expressed in the hippocampus and cerebral cortex during postnatal development. Neuroscience 95, 981-991. doi: 10.1016/s0306-4522(99)00514-x 
Torika, N., Asraf, K., Apte, R. N., and Fleisher-Berkovich, S. (2018). Candesartan ameliorates brain inflammation associated with Alzheimer's disease. CNS Neurosci. Ther. 24, 231-242. doi: 10.1111/cns.12802

Torika, N., Asraf, K., Cohen, H., and Fleisher-Berkovich, S. (2017). Intranasal telmisartan ameliorates brain pathology in five familial Alzheimer's disease mice. Brain Behav. Immun. 64, 80-90. doi: 10.1016/j.bbi.2017.04.001

Torika, N., Asraf, K., Danon, A., Apte, R. N., and Fleisher-Berkovich, S. (2016). Telmisartan modulates glial activation: in vitro and in vivo studies. PLoS One 11:e0155823. doi: 10.1371/journal.pone.0155823

Toscano, E. C. B., Vieira, E. L. M., Portela, A., Caliari, M. V., Brant, J. A. S., Giannetti, A. V., et al. (2020). Microgliosis is associated with visual memory decline in patients with temporal lobe epilepsy and hippocampal sclerosis: a clinicopathologic study. Epilepsy Behav. 102:106643.

Trigiani, L. J., Royea, J., Lacalle-Aurioles, M., Tong, X. K., and Hamel, E. (2018). Pleiotropic benefits of the angiotensin receptor blocker candesartan in a mouse model of Alzheimer disease. Hypertension 72, 1217-1226. doi: 10.1161/ HYPERTENSIONAHA.118.11775

Tsukuda, K., Mogi, M., Iwanami, J., Min, L. J., Sakata, A., Jing, F., et al. (2009). Cognitive deficit in amyloid-beta-injected mice was improved by pretreatment with a low dose of telmisartan partly because of peroxisome proliferatoractivated receptor-gamma activation. Hypertension 54, 782-787. doi: 10.1161/ HYPERTENSIONAHA.109.136879

Tzourio, C. (2007). Hypertension, cognitive decline, and dementia: an epidemiological perspective. Dialogues Clin. Neurosci. 9, 61-70. doi: 10.31887/dcns.2007.9.1/ctzourio

Verkhratsky, A., Olabarria, M., Noristani, H. N., Yeh, C. Y., and Rodriguez, J. J. (2010). Astrocytes in Alzheimer's disease. Neurotherapeutics 7, 399-412. doi: 10.1016/j.nurt.2010.05.017

Villapol, S., and Saavedra, J. M. (2015). Neuroprotective effects of angiotensin receptor blockers. Am. J. Hypertens. 28, 289-299. doi: 10.1093/ajh/hpu197

Villar-Cheda, B., Dominguez-Meijide, A., Joglar, B., Rodriguez-Perez, A. I., Guerra, M. J., and Labandeira-Garcia, J. L. (2012). Involvement of microglial RhoA/Rho-kinase pathway activation in the dopaminergic neuron death. Role of angiotensin via angiotensin type 1 receptors. Neurobiol. Dis. 47, 268-279. doi: $10.1016 /$ j.nbd.2012.04.010

Wang, D., Gelband, C. H., Sumners, C., and Posner, P. (1997). Mechanisms underlying the chronotropic effect of angiotensin II on cultured neurons from rat hypothalamus and brain stem. J. Neurophysiol. 78, 1013-1020. doi: 10.1152/ jn.1997.78.2.1013

Wang, J., Ho, L., Chen, L., Zhao, Z., Zhao, W., Qian, X., et al. (2007). Valsartan lowers brain beta-amyloid protein levels and improves spatial learning in a mouse model of Alzheimer disease. J. Clin. Invest. 117, 3393-3402. doi: 10.1172/ JCI31547

Wiesmann, M., Roelofs, M., van der Lugt, R., Heerschap, A., Kiliaan, A. J., and Claassen, J. A. (2017). Angiotensin II, hypertension and angiotensin II receptor antagonism: roles in the behavioural and brain pathology of a mouse model of Alzheimer's disease. J. Cereb. Blood Flow Metab. 37, 2396-2413. doi: 10.1177/ 0271678X16667364

Wolf, A. B., Valla, J., Bu, G., Kim, J., LaDu, M. J., Reiman, E. M., et al. (2013). Apolipoprotein E as a beta-amyloid-independent factor in Alzheimer's disease. Alzheimers Res. Ther. 5:38. doi: 10.1186/alzrt204

Wu, C. Y., Zha, H., Xia, Q. Q., Yuan, Y., Liang, X. Y., Li, J. H., et al. (2013). Expression of angiotensin II and its receptors in activated microglia in experimentally induced cerebral ischemia in the adult rats. Mol. Cell. Biochem. 382, 47-58. doi: 10.1007/s11010-0131717-4

Ye, S., Huang, Y., Mullendorff, K., Dong, L., Giedt, G., Meng, E. C., et al. (2005). Apolipoprotein (apo) E4 enhances amyloid beta peptide production in cultured neuronal cells: apoE structure as a potential therapeutic target. Proc. Natl. Acad. Sci. U.S.A. 102, 18700-18705. doi: 10.1073/pnas.05086 93102

Youmans, K. L., Tai, L. M., Nwabuisi-Heath, E., Jungbauer, L., Kanekiyo, T., Gan, M., et al. (2012). APOE4-specific changes in Abeta accumulation in a new transgenic mouse model of Alzheimer disease. J. Biol. Chem. 287, 41774-41786. doi: 10.1074/jbc.M112.407957

Zaldua, S., Damen, F. C., Pisharody, R., Thomas, R., Fan, K. D., Ekkurthi, G. K., et al. (2020). Epidermal growth factor treatment of female mice that express APOE4 at an age of advanced pathology mitigates behavioral and cerebrovascular dysfunction. Heliyon 6:e03919. doi: 10.1016/j.heliyon.2020. e03919

Zhao, N., Liu, C. C., Qiao, W., and Bu, G. (2018). Apolipoprotein E, receptors, and modulation of Alzheimer's disease. Biol. Psychiatry 83, 347-357. doi: 10.1016/j. biopsych.2017.03.003

Zhu, Y., Nwabuisi-Heath, E., Dumanis, S. B., Tai, L. M., Yu, C., Rebeck, G. W., et al. (2012). APOE genotype alters glial activation and loss of synaptic markers in mice. Glia 60, 559-569. doi: 10.1002/glia.22289

Conflict of Interest: GRJT was an inventor on patents owned by UIC.

The remaining authors declare that the research was conducted in the absence of any commercial or financial relationships that could be construed as a potential conflict of interest.

Copyright (C) 2021 Scheinman, Zaldua, Dada, Krochmaliuk, Dye, Marottoli, Thatcher and Tai. This is an open-access article distributed under the terms of the Creative Commons Attribution License (CC BY). The use, distribution or reproduction in other forums is permitted, provided the original author(s) and the copyright owner(s) are credited and that the original publication in this journal is cited, in accordance with accepted academic practice. No use, distribution or reproduction is permitted which does not comply with these terms. 